\title{
Revus
}

Journal for Constitutional Theory and Philosophy of Law / Revija za

ustavno teorijo in filozofijo prava

38 | 2019

Revus (2019) 38

\section{El carácter presuntivo de las presunciones absolutas}

The presumptiveness of conclusive presumptions

\section{Diego Dei Vecchi}

\section{(2) OpenEdition \\ Journals}

Electronic version

URL: http://journals.openedition.org/revus/5333

DOI: 10.4000/revus.5333

ISSN: $1855-7112$

\section{Publisher}

Klub Revus

\section{Electronic reference}

Diego Dei Vecchi, «El carácter presuntivo de las presunciones absolutas », Revus [Online], 38 | 2019,

Online since 12 December 2019, connection on 30 December 2019. URL : http://

journals.openedition.org/revus/5333; DOI : 10.4000/revus.5333

This text was automatically generated on 30 December 2019.

All rights reserved 


\title{
El carácter presuntivo de las presunciones absolutas
}

\author{
The presumptiveness of conclusive presumptions
}

\author{
Diego Dei Vecchi
}

\section{Introducción}

1 A pesar de la ubicuidad y del uso insistente de la expresión 'presunción iuris et de iure' en el discurso jurídico, tanto en el contexto académico cuanto en el judicial, no son pocas las voces que abogan por su supresión. Suelen argüirse dos consideraciones centrales en defensa de esta iniciativa. La primera de ellas apunta a que las disposiciones de las que a menudo se extraen normas (mal llamadas) presuntivas iuris et de iure o absolutas (en adelante PA) son reconducibles sin pérdida alguna a otros institutos con nombres propios, menos equívocos. La segunda se basa en que esos otros institutos a que las PA son reconducibles no poseen el rasgo central de las genuinas presunciones, a saber: tener una estrecha relación con cuestiones probatorias $\mathrm{o}$, por lo menos, con la aceptación de ciertas proposiciones fácticas como verdaderas. De modo que, por un lado, la expresión PA no está relacionada con ningún concepto singular y, por el otro, los institutos a que refiere no son siquiera auténticas presunciones.

2 Desde esta óptica, a la que denominaré reduccionista, en algunas ocasiones se alega que las normas de PA son ni más ni menos que reglas comunes de conducta mal disfrazadas, reglas que enlazan descripciones de ciertos actos genéricos con consecuencias jurídicas generalmente sancionatorias. En otras oportunidades se afirma que las supuestas normas de PA no son más que normas constitutivas o definiciones algo disimuladas, quizás incluso ficciones jurídicas. De cualquier modo, estas opciones conducen todas al mismo resultado, a saber: a generar normas sustantivas sancionatorias. Un ejemplo con ánimo meramente introductorio: imagínese un ordenamiento jurídico una de cuyas disposiciones instituye que 'todas aquellas personas que gestionen casas de juego deben ser sancionadas con cierta pena'. Supóngase que ese ordenamiento contiene otra disposición que establece que 'se presume iuris et de iure (o que se tiene por probado sin 
posibilidad de prueba en contrario, o que se asume sin más, o que se tiene por acreditado de modo irrefutable, etc. $\left.{ }^{1}\right)$ que todas las personas en cuya posisión es hallen máquinas tragaperras gestionan casas de juego'. Pues bien, según la tesis reduccionista, esta disposición no es sino un modo traspuesto -y por demás abstruso- de establecer que en ese ordenamiento deben ser sancionadas con la pena propia de la primera disposición todas aquellas personas que posean máquinas tragaperras. La segunda disposición aparenta expresar una presunción de gestión de casas de juego ante la verificación de la posesión de una máquina tragaperras, pero esta apariencia es solo producto de un ingenuo descuido. Desde la óptica del reduccionismo todo lo que de allí se extrae es, en última instancia, una norma que instituye una pena para la acción de poseer máquinas tragaperras.

3 Este trabajo se dirige a rechazar el reduccionismo. Se mostrará que reconducir las PA sea a normas sancionatorias, tales como tipos penales, sea a dispositivos de los cuales se infieren prohibiciones de carácter sustantivo, resulta inadmisible. Se argumentará que las PA no solo son auténticos casos de presunción, i.e. normas que determinan que ciertos enunciados fácticos deben ser tenidos como verdaderos, sino que pueden ser distinguidas a la luz de ciertas peculiaridades. En cualquier caso, vale aclarar desde ya, aunque creo que la peculiaridad que intentaré subrayar en lo que sigue distingue a muchas de las situaciones normativas que en el discurso jurídico suelen tratarse como casos de PA, mi interés no está tanto en tratar de justificar la calificación de un tal o cual conjunto de normas positivas como instanciación de ese concepto. Por el contrario, el objetivo del trabajo se enfoca más bien en otros dos puntos, a saber: primero, en mostrar las especiales características de ciertas situaciones potenciales a las que propondré reconducir la etiqueta PA; segundo, en sacar a la luz la relevancia práctica que esas peculiares estructuras argumentales podrían tener.

Procederé del siguiente modo. En el parágrafo § 2 explicitaré qué es lo que entiendo por 'presunción', poniendo el foco de atención en una de las acepciones de este término. Se distinguirá allí, además, entre presunciones iuris y presunciones hominis. En el $\S 3$ presentaré las principales tesis del reduccionismo mencionando las razones sobre cuya base se niega autonomía conceptual y relevancia práctica a la noción de PA. En el $\$ 4$ argumentaré que hay un espacio conceptual no reducible dentro del cual propondré situar a las genuinas PA. En el $\S 5$, por último, mostraré cuál es la relevancia práctica de incluir esta noción de PA dentro de nuestro acervo conceptual, en contra de lo que el reduccionismo supone.

\section{El lugar de las presunciones en el discurso jurídico}

5 No es fácil determinar qué es una presunción. El término adolece de una buena dosis de ambigüedad, no solo en el lenguaje ordinario sino, especialmente, dentro del discurso jurídico. ${ }^{2}$ En este marco discursivo, algunas de las acepciones que el término posee en el lenguaje ordinario pierden relevancia: por ejemplo, aquellas vinculadas con la exhibición de ciertos rasgos personales o habilidades, o con el empeño en el cuidado de la propia persona. Mas en el discurso jurídico, una de las acepciones del vocablo ordinario 'presunción' asume un papel central como término primitivo. Esa acepción es la siguiente:

Acción y efecto de suponer o considerar algo por los indicios o señales que se tienen. ${ }^{3}$ 
6 En este sentido, presumir es aceptar una determinada proposición fáctica qua verdadera. Podría decirse que las razones adecuadas para aceptar una proposición como verdadera son las llamadas razones epistémicas, i.e. las pruebas; solo ellas habrían de contar como 'indicios o señales'. ${ }^{4}$ De allí que tenga sentido decir que una presunción, en la medida en que opera justificando la aceptación de una proposición qua verdadera, tiene una estrecha vinculación con cuestiones 'de prueba' en un sentido sumamente lato de la palabra. En efecto, esa vinculación se da con muy diversos matices, los cuales solo pueden verse claramente si se desglosa el argumento que conduce al resultado presuntivo, i.e. a aceptar la proposición en cuestión. ${ }^{5}$

7 Esto último deja entrever que, aun restringiendo el sentido del término a su faceta probatoria, 'presunción' sigue resultando enormemente ambiguo respecto de esa faceta específica. Ante todo, el vocablo adolece de la ambigüedad 'proceso-producto': con él puede designarse ya al argumento que justifica aceptar un cierto enunciado fáctico qua verdadero, ya al enunciado mismo. ${ }^{6}$ En lo que sigue habrá de ponerse el foco de atención, sobre todo, en esta última acepción del término bajo consideración. ${ }^{7}$

8 Sin embargo, incluso cuando referida al proceso argumental justificativo de la aceptación de una proposición qua verdadera, 'presunción' alude a cosas distintas. Entre juristas se han identificado desde antaño distintos modos de presunción (i.e. de argumento presuntivo). A efectos de deslindar las dos mayores clases de argumento presuntivo se suelen usar las etiquetas 'presunciones iuris' o 'legal', por un lado, y 'presunciones hominis' o 'naturales', por el otro. La estructura de argumento que Stephen Toulmin popularizó a partir de 1958 constituye un recurso sumamente esclarecedor a efectos de situar la diferencia entre estos dos tipos de argumento presuntivo. ${ }^{8}$ Para él, todo argumento se dirige a dar apoyo a una cierta pretensión [claim], en cuyo sustento se invocarán normalmente ciertas consideraciones. Esas consideraciones constituyen lo que Toulmin denomina razones [grounds]. Cuando se cuestiona el paso de las razones a la pretensión, i.e. cuando se pone en duda la capacidad justificativa de esas consideraciones, se torna necesario poner de manifiesto la garantía [warrant] del argumento. ${ }^{9}$ La garantía consiste en la regla que autoriza el paso de las consideraciones que ofician de razones a la pretensión defendida. Esta regla,

estaría constituida por las máximas de experiencia, las presunciones y otro tipo de enunciados generales que correlacionan el tipo de hechos señalados en las razones con el tipo de hechos señalados en la pretensión. ${ }^{10}$

9 Mas sería posible cuestionar también la aceptabilidad de la garantía, de la regla misma. Es aquí donde se torna imperioso poner de manifiesto el respaldo [backing] que cimienta la regla invocada. Los respaldos que cimientan reglas de garantía adoptan distinto cariz según el campo de argumentación dentro del cual desempeñen su función. ${ }^{11}$ En ocasiones ese respaldo reposa en la observación y en la experiencia pasadas, pero no todos los argumentos poseen esa índole de cimiento en sus estratos más profundos.

10 Sobre esta base es posible trazar la distinción entre presunciones iuris y presunciones hominis. La diferencia entre ellas ha de buscarse, en efecto, en el diverso cariz del respaldo que sustenta las consideraciones que hacen de garantías en uno $u$ otro tipo de argumento. Estipularé, de conformidad con una usanza bastante compartida que siempre que la garantía encuentre su respaldo en la experiencia, en la observación del mundo, la razón implicada en el argumento habrá de denominarse indicio. ${ }^{12}$ En este sentido, un indicio es una razón dada en favor de un enunciado fáctico (pretensión) cuya garantía es una máxima de la experiencia, esto es, una generalización respaldada 
en la observación del mundo. ${ }^{13}$ Es a los argumentos de esta clase que suele identificárselos como presunciones hominis, simples, o naturales: razonamientos teóricos, una de cuyas premisas (la garantía) está constituida por un enunciado (hipotético) respaldado inductivamente. Quizás esta sea el sentido primitivo de 'presunción', la acepción más usual con que el término se emplea tanto en el lenguaje ordinario -tal como indica la definición lexicográfica antes traída a colación- como en el literario y el filosófico, i.e. como sinónimo de inferencia probatoria. Es este el modo en que Sherlock Holmes emplea el término cuando, en The Boscombe Valley Mystery, justifica frente a Watson su conclusión de que McCarthy esperaba a alguien que había estado en Australia:

Well, obviously it could not have been meant for the son. The son, as far as he knew, was in Bristol. It was mere chance that he was within earshot. The 'Cooee!'was meant to attract the attention of whoever it was that he had the appointment with. But 'Cooee' is a distinctly Australian cry, and one which is used between Australians. There is a strong presumption that the person whom McCarthy expected to meet him at Boscombe Pool was someone who had been in Australia. ${ }^{14}$

11 Así, una presunción hominis es ni más ni menos que una inferencia probatoria respaldada en última instancia en un razonamiento inductivo. ${ }^{15}$ No es posible ni necesario involucrarse aquí con los problemas relativos a la inducción, ni con los relativos a la posibilidad de una racionalidad inductiva. Alcanza en este marco con resaltar un lugar común a este respecto, a saber: que todo enunciado general inductivamente fundado es irremediablemente provisorio y falible. Es en buena medida por esta razón que a los argumentos presuntivos hominis se les atribuye la propiedad de ser derrotables, en el sentido de que siempre habrá de admitirse como (lógicamente) posible una observación que falsee el enunciado general en que ellos se apoyan. Llamaré a este fenómeno derrotabilidad empírica. ${ }^{16}$

En contraste, en el discurso jurídico es usual defender pretensiones invocando razones a partir de cuya verificación (se considera que) resulta jurídicamente obligatorio aceptar qua verdadero el enunciado con que la pretensión se identifica. Así, muchos ordenamientos contienen normas de conformidad con las cuales, por ejemplo, si un cierto relato $\mathrm{R}$ está contenido en un documento público (o un documento con ciertas características formales), debe asumirse que $\mathrm{R}$ se corresponde con los hechos acaecidos, i.e. es obligatorio tener a $\mathrm{R}$ por verdadero. Cuando el paso de las consideraciones invocadas como razones a la pretensión resulta de tal modo impuesto por una norma jurídica estaremos ante una presunción iuris.

13 Esto exige hacer algunas precisiones terminológicas adicionales, dado que la expresión 'presunción iuris' es, ella también, empleada con cierta ambigüedad en el discurso jurídico. A veces se alude con esa expresión a la regla de garantía del argumento, otras veces se alude con ella al argumento al que esa garantía fundamenta en su totalidad, e incluso en ocasiones se hace referencia más bien a la conclusión de este último. Denominaré a lo primero 'norma presuntiva', a lo segundo 'presunción iuris' y a lo tercero 'enunciado presumido'. Por su parte, llamaré a las razones implicadas en este tipo de argumento 'hechos base'. Así entendida, una presunción iuris es un argumento que tiene por premisa menor o razón a un hecho base, por premisa mayor o garantía a una norma presuntiva y por pretensión al enunciado presumido. ${ }^{17} \mathrm{Un}$ cuadro comparativo puede resultar de ayuda.

\begin{tabular}{|l|l|l}
\hline Estrato del argumento & Presunción hominis & Presunción iuris \\
\hline
\end{tabular} 


\begin{tabular}{|l|l|l|}
\hline (a) Pretensión & Enunciado fáctico & Enunciado presumido \\
\hline (b) Razón & Indicio & Hecho base \\
\hline (c) Garantía & Máxima de experiencia & Norma presuntiva \\
\hline (d) Respaldo & Observación & ¿Razones subyacentes? \\
\hline
\end{tabular}

Las normas presuntivas iuris imponen a quien juzga una obligación de aceptar un enunciado como verdadero y emplearlo como premisa de ulteriores argumentos. ${ }^{18} \mathrm{En}$ este sentido, las presunciones iuris no constituyen genuina prueba. De hecho, podría decirse que ellas son un "sucedáneo" de la prueba que termina en una "imposición directa" del resultado al juez. ${ }^{19} \mathrm{~A}$ pesar de esto, sigue pareciendo sensato decir que entre presunción iuris y prueba hay una estrecha relación: al menos en el sentido de que las presunciones iuris vienen a reemplazar la tarea de la inferencia probatoria determinando que ciertas proposiciones fácticas deben ser tenidas por verdaderas. ${ }^{20}$ Sea como fuere, un rasgo crucial de estas normas es que ellas forman parte del llamado "sistema secundario", no estando dirigidas directamente a la ciudadanía. Es decir, son normas dirigidas a la judicatura que imponen obligaciones relativas a cómo justificar las decisiones a adoptar. ${ }^{21}$

Ahora bien, ha sido usual en la dogmática distinguir las normas presuntivas según admitan o no la invocación y verificación de la derrotabilidad característica de las presunciones hominis, esto es, la derrotabilidad empírica. Así, en la mayor parte de las ocasiones, se asume, la norma presuntiva prescribe el paso del hecho base al presumido a menos que se pruebe la falsedad de este último. Como puede verse, este tipo de presunciones, llamadas por lo común iuris tantum, devienen derrotables en el mismo sentido en que lo son las presunciones hominis. ${ }^{22}$ De allí que se diga a menudo que la presunción iuris tantum cumple una función procesal o dialéctica al imponer la carga de la prueba del hecho contrario al presumido a aquella persona que se vería perjudicada en virtud de la aceptación del enunciado presunto. ${ }^{23}$

En contraste, al menos en apariencia, habría versiones de presunciones iuris que excluyen la posibilidad de prueba en contrario. Se trataría de normas presuntivas que imponen la aceptación del enunciado presumido (iuris, claro está) una vez verificado el hecho base, excluyendo de plano toda indagación, discusión o análisis adicional. Pues bien, son precisamente estas las normas a las que en el discurso jurídico se ha venido denominando, con mayor o menor fortuna, presunciones iuris et de iure o absolutas o irrefutables. Estas normas hacen que la 'estructura argumental' de la que forman parte quede, en apariencia, especialmente reforzada:

In a word, they are inferences which the law makes so peremptorily, that it will not allow them to be overturned by any contrary proof, however strong. ${ }^{24}$

17 En suma, según la reconstrucción precedente, podríamos decir entonces que las presunciones, en el estricto sentido en que aquí nos interesan, son argumentos en virtud de los cuales:

a. ciertos hechos base (indicios o datos presuntivos, respectivamente) se enlazan con ciertos enunciados fácticos (pretensiones) que son tenidos por verdaderos;

b. por medio de un lazo o garantía que puede ser bien normativo (norma presuntiva iuris), bien experiencial (máxima de experiencia); ${ }^{25}$

c. justificando la aceptación del enunciado fáctico de que se trate a efectos de emplearlo, eventualmente, como premisa de un razonamiento más amplio. ${ }^{26}$ 
18 Pretendo mostrar que, a pesar de que muchas veces se reniega de ello, todo esto puede predicarse sin más de las llamadas PA, o por lo menos de aquellas que ejemplifiquen ciertos tipos de situación normativa que intentaré elucidar. Pero veamos primero las razones por las cuales se reniega del carácter presuntivo de las PA.

\section{Las presunciones iuris et de iure frente al reduccionismo}

El reduccionismo ataca sin más la explicación de las PA como casos de genuina 'presunción' sin posibilidad de prueba en contrario. El reduccionista piensa que se trata de una caracterización engañosa dado que las PA nada tienen que ver con la prueba de un enunciado y ni siquiera con la imposición de su aceptación qua verdadero. En contraste, se trataría de situaciones en que ese enunciado (solo aparentemente presumido) se torna normativamente irrelevante, casos en los cuales simplemente se alteran los supuestos de hecho de ciertas normas sustantivas.

Se ha señalado que una de las más grandes dificultades para elucidar qué son las PA radica en la ausencia de casos paradigmáticos de presunciones tales en contraste con las múltiples alusiones a ellas en el discurso jurídico. ${ }^{27} \mathrm{Creo}$, en consonancia con esta impresión, que los intentos por elucidar las PA se han visto muchas veces oscurecidos por los ejemplos empleados a esos efectos; ejemplos a menudo adoptados sobre la base de alusiones a PA halladas dentro del discurso jurídico, especialmente el tribunalicio. Uno de los ejemplos invocados - lo cual genera de por sí ciertas perplejidades - ha sido el de la disposición que establece una sanción para quien circule más allá de un cierto límite de velocidad máxima, supongamos:120 km/h. En este caso la supuesta PA apuntaría a la generación de un riesgo para el resto de la comunidad. Muchas personas han sostenido que difícilmente pueda entenderse a esas normas como siendo, en sí mismas, expresivas de normas presuntivas. En el mejor de los casos, esas disposiciones expresan normas de deber que presuponen una presunción (hominis) que opera como razón subyacente de la norma. ${ }^{28}$ Algo parecido parece suceder frente a normas como aquellas que determinan la edad a partir de la cual la ciudadanía adquiere la mayoría de edad: sería como mínimo engañoso presentar a normas tales como presunciones de alguna clase; ellas serían, más bien, definiciones. ${ }^{29}$ Entende disposiciones semejantes como expresiones de normas presuntivas distorsionaría sin dudas el modo en que opera el razonamiento jurídico.

21 En efecto, imaginemos un ordenamiento jurídico OJ. Supongamos que el intérprete, debiendo resolver un caso en que una persona es denunciada por haber estado conduciendo a $130 \mathrm{~km} / \mathrm{h}$, solo halla en las fuentes del derecho la siguiente disposición: D: Será condenada a prisión por $x$ días toda persona que conduzca a más de $120 \mathrm{~km} / \mathrm{h}$.

22 Al menos en principio podría parecer forzado decir que esa sola disposición expresa o establece una norma presuntiva iuris et de iure. Comprometerse con semejante afirmación requeriría extraer de esa disposición dos normas distintas: una que prohíba, por caso, generar un riesgo al conducir, y otra estrictamente presuntiva que ordene tener por verdadera la generación de ese riesgo si se acredita la conducción a más de $120 \mathrm{~km} / \mathrm{h}$. Quienes estén más familiarizados con el escepticismo en materia interpretativa seguramente no se sobresaltarían ante propuestas de este talante. Después de todo, las normas presuntivas absolutas, como toda otra norma, son 
significados de disposiciones normativas extraídos por vía interpretativa. Mas admitamos por ahora que una propuesta semejante de reconstrucción del sistema normativo a emplear a efectos de resolver el caso sería un tanto extravagante. En este sentido, es bastante sugestivo que sea precisamente este el ejemplo empleado en ocasiones desde el reduccionismo a efectos de impugnar la noción de PA; pues se trata de un ejemplo que facilita en demasía la conclusión de que esa expresión es una etiqueta vacía, casi absurda. En efecto, lo atinado de la postura reduccionista depende de cómo se reconstruya el sistema normativo que funja de base para la explicación, al tiempo que la reconstrucción antedicha no se muestra muy plausible a primera vista. ${ }^{30}$

A efectos de eludir esa extravagancia y la consecuente reducción al absurdo de la noción de PA, imaginemos otro ordenamiento $\mathrm{OJ}_{1}$ algo menos austero. Supongamos que ese ordenamiento contiene no ya tan solo una sino dos disposiciones. Una de ellas establece que:

$\mathrm{D}_{1}$ : Será condenada a prisión por $x$ días toda persona que conduzca generando un riesgo a la comunidad.

La otra dispone:

$\mathrm{D}_{2}$ : se presumirá iuris et de iure (o bien: 'se tendrá por probado sin posibilidad de prueba en contrario', o 'se asumumirá sin más', o 'se tendrá por acreditado de modo irrefutable', etc.) la generación de un riesgo para la comunidad toda vez que se conduzca a más de $120 \mathrm{~km} / \mathrm{h}$.

Este último modo de presentar la cuestión se asemeja al ejemplo esbozado al inicio, o incluso a otro ejemplo alegado con mucha frecuencia como un caso paradigmático de PA, a saber: el de los tipos penales que condenan abusos sexuales - actos sexuales contra el consentimiento de quien se convierte en víctima - en consonancia con otras disposiciones que establecen que se presumirá iuris et de iure la falta de consentimiento si la persona con la que se mantuvieron relaciones sexuales no tiene una cierta edad. ${ }^{31}$

Como dije, comparto la inquietud de conformidad con la cual los ejemplos traídos usualmente a colación para explicar lo que son las PA no resultan esclarecedores. Creo que lo mejor a efectos sortear esta dificultad es abandonar los ejemplos y trabajar con un esquema abstracto. Apelar a una abstracción resulta útil por dos razones. En primer lugar, porque permite ver más claramente la singularidad de los esquemas argumentativos a los que propondré reconducir la etiqueta PA. En segundo lugar, porque permite aislar a estas presunciones de consideraciones específicas vinculadas con muchos de los ejemplos usualmente empleados (consideraciones morales, por ejemplo). Esas consideraciones podrían tornar discutible la subsunción de un cierto ejemplo en el concepto estricto de PA. Podría ser el caso que, aunque de ciertas disposiciones podrían extraerse PA, interpretaciones tales resulten inconstitucionales, inmorales, etc. Pero el hecho de que una interpretación tal pueda resultar impugnable no tiene por consecuencia necesaria la eliminación del concepto mismo ni de su utilidad práctica, al menos potencial. Si se verificase luego que no hay caso alguno reconducible a ese concepto, habrá que declarar vacía la clase (al menos a la luz de un cierto ordenamiento normativo), pero esto sería una operación ulterior. Pero el hecho de que la clase haya de declararse vacía no implica, todavía, que ella sea prácticamente inútil, como sugeriré sobre el final de este ensayo. 
Supongamos entonces, a efectos de generar nuestro esquema abstracto, un sistema normativo $\mathrm{S}_{1}$, producto de la interpretación iterada de dos disposiciones del ordenamiento $\mathrm{OJ}_{1}, \mathrm{D}_{1}$ y $\mathrm{D}_{2}$, que queda constituido del siguiente modo: ${ }^{32}$

$\mathrm{S}_{1}$

$\mathrm{N}_{1}$ (interpretación de $\mathrm{D}_{1}$ ): $\mathrm{A} \rightarrow \mathrm{OC}$.

$\mathrm{N}_{2}$ (interpretación de $\mathrm{D}_{2}$ ): $\mathrm{B} \rightarrow \mathrm{O}_{[\mathrm{PA}]} \mathrm{A} \cdot{ }^{33}$

Frente a $\mathrm{OJ}_{1}$ el reduccionismo insiste negando también que normas como $\mathrm{N}_{2}$ instancien auténticos casos de PA. De conformidad con esa postura las PA no poseen singularidad conceptual ni relevancia práctica alguna, ni siquiera frente a ordenamientos menos modestos que $\mathrm{OJ}$, como $\mathrm{OJ}_{1}$. De hecho, normas semejantes no podrían ser presuntivas, dado que estas últimas (a) establecen 'verdades procesales' (en nuestros términos: obligan a aceptar proposiciones como verdaderas), al tiempo que (b) esas verdades son vencibles, derrotables. En este orden de ideas se ha dicho que:

\footnotetext{
la idea de una verdad procesal (entendida como verdad en el proceso) no derrotable suena realmente muy extraña, tiene algo de paradójica o contradictoria [...] o bien abandonamos la caracterización que hemos hecho de las normas de presunción en términos de verdad procesal [...] para poder incluir a las normas que dan pie a los juristas para hablar de presunciones iuris et de iure. O bien salvamos esa caracterización y mostramos que estas normas nada tienen que ver con la noción de verdad procesal (de verdad en el proceso). ${ }^{34}$
}

De allí que suela sostenerse que las PA no son más que normas sustantivas disfrazadas, normas que nada tienen que ver con la verdad del hecho (solo en apariencia) presumido. Normas del tipo $\mathrm{N}_{2}$ no son más que contradicciones en sus términos: el sistema debe explicitarse de otro modo. El reduccionismo colige de todo ello que, ante disposiciones como las conjeturadas en nuestro ejemplo, y ante lo inaceptable de reconstruir al sistema normativo en términos de $\mathrm{S}_{1}$, dicho sistema ha de reducirse a sistemas del tipo $\mathrm{S}_{2}$ :

$\mathrm{S}_{2}$

$\mathrm{N}_{1}: \mathrm{A} \rightarrow \mathrm{OC}$.

$\mathrm{N}_{3}: \mathrm{B} \rightarrow \mathrm{OC}$.

Es decir: $S_{1}$ establece que (a) está prohibido A (i.e. que ha de ser condenado quien ejecute A) y que (b) siempre que se dé B se presumirá como verdadero A sin posibilidad de prueba en contrario. De conformidad con $\mathrm{S}_{2}$, en cambio, más directa y llanamente, lo prohibido (i.e. lo condenable) son tanto A cuanto B. Se trataría de un sinceramiento porque esa reconstrucción del sistema hace explícito, sin más, lo que ya estaría ocurriendo en $\mathrm{S}_{1}$, a saber: que toda vez que se verifique $\mathrm{B}$, A deviene normativamente irrelevante; que en última instancia lo prohibido y sancionado por la norma que $\mathrm{D}_{2}$ expresa es la conducta B. ${ }^{35}$ Así:

Este mecanismo [el de las supuestas presunciones iuris et de iure] opera mediante la modificación de los presupuestos fácticos que la norma contempla para la producción de efectos jurídicos. Tal modificación opera, por un lado extrayendo el hecho presumido como requisito de la aplicación de la norma, sustituyéndolo por otro hecho (o conjunto de hechos) de cuya prueba se condiciona la aplicación de la norma. $^{36}$

La amplia difusión de esta idea había llevado hace ya muchos años a una afirmación categórica: 
All authorities agree that a so-called "conclusive presumption" is really a rule of substantive law. ${ }^{37}$ defienden esta concepción estiman que la norma que tiene al hecho base por antecedente $\left(\mathrm{N}_{3}\right)$ se infiere de una norma intermedia que es una ficción. Cabe resaltar que decir al mismo tiempo que las PA son casos de ficción jurídica y que son normas prescriptivas ante las cuales el hecho presumido se torna normativamente irrelevante sería inconsistente; pues las ficciones no parecen, a su vez, reducibles a normas de conducta. Pero dejando esto al margen, en esta nueva reinterpretación las normas de PA serían ficciones y las normas prescriptivas serían producto de un razonamiento que tiene a la norma de PA/ficción jurídica como premisa. Así, si se elige esta segunda estrategia reduccionista, la situación normativa sería la siguiente: ${ }^{40}$

$\mathrm{N}_{1}: \mathrm{A} \rightarrow \mathrm{OC}$

$\mathrm{N}_{2,}: \mathrm{B} \rightarrow \mathrm{O}_{[\text {hacer como si }]} \mathrm{A}$.

$\mathrm{N}_{3}: \mathrm{B} \rightarrow \mathrm{OC}$

En efecto, hay poca diferencia, salvo en la forma de su expresión, entre una

presunción irrefutable y lo que simplemente llamamos una regla jurídica. ${ }^{38}$

norma que castiga la acción B. De allí que el reduccionismo deba recurrir a alguna estrategia de derivación. Por ejemplo, alguien podría alegar que $\mathrm{N}_{3}$ es una norma implícita, producto directo de la transitividad del condicional aplicada a $\mathrm{N}_{1}$ y a $\mathrm{N}_{2}$. $\mathrm{Al}$ menos con la siguiente lectura:

$\mathrm{N}_{1}: \mathrm{A} \rightarrow \mathrm{OC}$

$\mathrm{N}_{2}: \mathrm{B} \rightarrow \mathrm{OA}$

$\mathrm{N}_{3}: \mathrm{B} \rightarrow \mathrm{OC}$

hipótesis, resultado de una muy extravagante interpretación de $\mathrm{D}_{2}$, la transitividad del condicional no aplica a la lógica deóntica; banalmente, porque el consecuente de la primera premisa no se condice con el antecedente de la segunda ${ }^{39}$.

De allí se seguiría,

Ahora bien, en la medida en que las ficciones jurídicas se definan como casos en que la verdad del enunciado fáctico se asume como verdadero a despecho de su sabida falsedad, y quizás precisamente en virtud de ella, entonces parece haber una diferencia innegable con las PA. Es precisamente esta la noción de ficción jurídica presente en el clásico trabajo de Fuller: las ficciones son o bien enunciados postulados con consciencia plena o parcial de su falsedad, o bien enunciados falsos a los que se les reconoce una cierta utilidad. ${ }^{41}$ Por ejemplo, imagínese una norma que dijese que a los efectos de los derechos del nasciturus se lo tratará como si hubiera nacido, o una que estableciese que, publicados ciertos edictos por tantos o cuantos días, se hará como si la citación se 
hubiera entregado en persona, o que a los efectos de la aplicación de la ley los extranjeros serán tratados como si fueren ciudadanos nativos.

En contraste, los casos tratados bajo la etiqueta de PA apuntan usualmente a circunstancias en donde el enunciado fáctico presumido se tiene de veras por acaecido, en virtud de la comprobación de otro evento. Tener por verdadero un enunciado sabidamente falso no es lo mismo que tener por verdadero un enunciado cuya verdad se ignora, aun si prohibiendo ir más allá en la indagación de su verdad o falsedad; y no sería lo mismo ni siquiera cuando las consecuencias prácticas fuesen idénticas. ${ }^{42}$

Un aspecto que hace patente la diferencia entre PA y ficciones jurídicas así entendidas es la total implausibilidad de pensar en casos recalcitrantes relativos a las ficciones, al tiempo que es muy fácil imaginar casos tales frente a PA..$^{43}$ En efecto, no parece tener mucho sentido pensar en casos de no nacidos nacidos, ni en casos de no notificados personalmente notificados personalmente, ni en casos de extranjeros nacionales. No es que no pueda haber sobreinclusión o infrainclusión respecto de las normas que establecen ficciones jurídicas, ${ }^{44}$ por cierto: bien podría ser que las razones subyacentes a la norma que establece la ficción no apliquen a un caso particular por la razón que fuere. La cuestión es que la sobre e infra inclusión no podrían jamás, en el caso de las ficciones, ser producto de la falsedad del hecho ficticiamente asumido. Es decir, el caso no podría ser recalcitrante solo en virtud de que el hecho que se creía falso y que fue asumido como verdadero por imperio de la ficción (e.g. que se trata de un nacido) era, después de todo, verdadero. Más que de casos recalcitrantes se trataría de eventualidades en que la norma que establece la ficción habría sido innecesariamente aplicada en virtud de deficiencias o errores epistémicos (i.e. lo que se creía falso, no lo era). En contraste, en las situaciones normativas como las que estamos tratando de singularizar aquí es perfectamente posible pensar en casos cuyo carácter recalcitrante reside, precisa y exclusivamente, en la falsedad del enunciado presumido como verdadero.

41 El reduccionista podría contraatacar alegando que no es forzoso aceptar un concepto así circunscripto de ficción jurídica. El abandono de ese concepto y la adopción de uno más amplio harían quizás que estas objeciones devengan obsoletas. ${ }^{45}$ De hecho, se las ficciones jurídicas podrían identificarse con normas constitutivas, con definiciones o con atajos normativos. Esto reduciría indirectamente las PA a esas categorías. Más aún, el reduccionista de las PA podría incluso deshacerse de la noción de ficción y reducir directamente las normas de PA a alguno de estos nuevos conceptos en juego. Todo ello sobre la base de un razonamiento como el siguiente:

$\mathrm{N}_{1}: \mathrm{A} \rightarrow \mathrm{OC}$

$\mathrm{N}_{2, \cdots}$ : B cuenta como A [norma constitutiva];

o bien,

$\mathrm{N}_{2^{\prime \prime},:}: \mathrm{B}$ es A [definición]

o bien,

$\mathrm{N}_{2^{\prime \prime},:}$ : B posee la misma regulación que A.

De cualquiera de esas alternativas se seguiría,

$\mathrm{N}_{3}: \mathrm{B} \rightarrow \mathrm{OC}$

Es alguna reconstrucción de este tipo la que podría sostener la pretensión reduccionista según la cual el vocabulario de las PA no es más que un giro lingüístico inútil. Frente a 
estas reconstrucciones, debe decirse desde ya, la norma presuntiva no es del todo inerte, pues interviene como premisa en un razonamiento del cual se extrae la norma prohibitiva implícita. Pero lo que el reduccionismo subraya es que emplear el giro lingüístico 'presuntivo' es innecesario, casi engañoso. Pues lo mismo sería expresable en términos mucho más simples diciendo que $B$ es reprochable y está sujeto a condena tanto cuanto A; al tiempo que, si se da B, A se torna irrelevante. Desde esta óptica, las pretendidas normas de PA, las supuestas normas presuntivas iuris et de iure, son siempre normas propias del "sistema primario o del súbdito". De modo que, si las normas presuntivas genuinas iban siempre dirigidas a la judicatura, las normas de PA no son presunciones en absoluto:

These are not, however, properly 'presumptions' that mandate an inference from a proven fact $p$ to a further fact $q$; they are disguised substantive rules of law that help define the relevant offence, which should be honestly expressed as such. ${ }^{46}$

Mostrar que la diferencia entre reconstruir de uno u otro modo el sistema normativo de referencia trasciende a la mera forma de expresión es el objetivo del resto de este trabajo.

\section{$4 \mathrm{~A}$ la búsqueda de las presunciones iuris et de iure}

Las distintas estrategias reduccionistas analizadas en el apartado anterior coinciden en asumir que, desde la perspectiva de la autoridad normativa, solo hay una opción justificativa y que ella consiste en equiparar el reproche de B al de A o bien, lisa y llanamente, en tornar irrelevante A toda vez que B sea el caso. Sin embargo, es posible pensar en un modo adicional de justificación y es plausible sostener que es este tipo de justificación lo que caracteriza a las PA. ${ }^{47}$

En su clásico artículo dedicado al análisis de las presunciones, Ullman-Margalit se centra especialmente en las peculiaridades justificativas de los distintos tipos de argumento presuntivo. En términos toulminianos, como se dijo, los rasgos distintivos de las presunciones pueden develarse mirando hacia aquello que funge de respaldo de las reglas de garantía: la presunción hominis tiene por garantía a una máxima de experiencia, la presunción iuris está garantizada por una norma. ${ }^{48}$ Para UllmanMargalit, lo que caracteriza a las presunciones iuris es que los cimientos de esas normas habrán de consistir en uno de tres tipos de consideraciones, a saber: inductivoprobabilísticas, evaluativas o procesales.

Las primeras no son otra cosa que aquellas consideraciones que sustentarían las máximas de experiencia de las presunciones hominis. ${ }^{49}$ Evidentemente, si la garantía de una presunción iuris estuviera sustentada de este modo, a ella subyacería una presunción hominis. Pero esto, se sostiene, no es condición necesaria ni de la presencia ni de la validez de normas presuntivas. ${ }^{50}$ Por lo demás, si el respaldo de la norma presuntiva fuera (solamente) el que fundamenta a la presunción hominis, lo único que la norma haría es dotar de un especial valor al enunciado producto de una inducción. Ello podría ser relevante si en ausencia de esa cualificación normativa dicho sustento resultase insuficiente a efectos de justificar la aceptación del enunciado fáctico en cuestión..$^{51}$ La norma presuntiva vendría a otorgar a la presunción hominis subyacente una fuerza especial de la cual carecería si valorada en términos meramente epistémicos. Si la presunción hominis constituyese, en cambio, prueba suficiente de por sí para la aceptación del enunciado fáctico aun en ausencia de presunción iuris, esta 
última devendría superflua. ${ }^{52}$ En este sentido, si no son superfluas, las normas presuntivas iuris habrán de justificarse siempre acudiendo a consideraciones de otra índole.

De hecho, se ha dicho muchas veces que lo que caracteriza propiamente a las presunciones iuris es el estar sustentadas en consideraciones de carácter evaluativo; ${ }^{53}$ consideraciones que conciernen en general (i) ya a la pregunta acerca de qué tipo de error es moral o socialmente más aceptable, (ii) ya a la evaluación moral o social del efecto regulador que la norma presuntiva podría tener en la conducta de la ciudadanía. 54

51 Pues bien, el tipo de reflexión de Ullman-Margalit es decisivo para entender bajo qué condiciones una PA puede ser comprendida como una auténtica presunción. ${ }^{55}$ Una norma como $\mathrm{N}_{2}$ será una norma presuntiva iuris et de iure (y no un mero dispositivo para inferir una norma sustantiva del tipo $\mathrm{N}_{3}$ ) al menos cuando su justificación consista en que:

i. B (i.e. el pretendido hecho base de la PA) es una razón (epistémica, un indicio) para presumir (hominis) que A (i.e. el antecedente de la norma sustantiva en cuestión) ha ocurrido, al tiempo que

ii. hay buenas razones (prácticas, evaluativas) para prohibir seguir indagando si A ha efectivamente acaecido toda vez que se prueba B.

52 Aunque la definición se propone en términos de razones prácticas, esto es tan solo una opción a efectos de dar generalidad al planteo. Nada impide reemplazar esa terminología por la de las reglas y los principios. Así, una norma será una norma de PA en tanto obligue a tener por verdadera una conducta o una situación fáctica $\mathrm{A}$, enlazada con una determinada consecuencia jurídica $\mathrm{C}$, sin posibilidad de prueba en contrario, toda vez que se verifique $B$, en virtud de que:

i. B es un indicio de A (por la validez de una presunción hominis que conduce de B a A); al tiempo que,

ii. hay otro estándar normativo, como una regla o un principio, que prohíbe seguir profundizando en la indagación acerca de si A es o no efectivamente el caso en cada ocasión en que se dé B o que, al menos, justifica imponer dicha prohibición. En otras palabras, hay alguna norma que establece o justifica establecer que B es una razón epistémica suficiente para aceptar que A y para prohibir toda indagación adicional.

53 Ni la noción de ficción jurídica ni la de definición o regla constitutiva, ni la simplificación de las PA en prohibiciones a secas captan estas singularidades: en los casos de normas de PA la verdad del supuesto de hecho presumido (e.g. A) es justificativamente crucial, en ella reside el reproche, aun cuando -más allá del hecho base (e.g. B)- se limite por completo la indagación judicial adicional respecto del primero. ${ }^{56}$

54 En este orden de ideas, y de conformidad con la estipulación terminológica precedente, una presunción iuris et de iure (i.e. una PA) sería un argumento cuya regla de garantía es una norma presuntiva de PA: una cuya justificación subyacente se estructura de un modo tal que conjuga razones de la case (i) y (ii). ${ }^{57} \mathrm{La}$ relevancia del hecho base radica en que se trata de un hecho epistémicamente relevante (i.e. un indicio) que opera además de algún modo contribuyendo a la justificación del bloqueo de toda indagación ulterior. Ello podría deberse, por ejemplo, a los costos que implicaría seguir investigando una vez que se cuenta con ese indicio o dado el menoscabo que seguir investigando o discutiendo sobre la cuestión podría generar a ciertos valores 
protegidos por el ordenamiento. Ante consideraciones tales, se juzga que el mencionado indicio debe tenerse por suficiente sin más a efectos de aceptar como verdadero el enunciado presumido.

De este modo, en las situaciones normativas que me interesa destacar hay dos prohibiciones en juego. Por una parte, la prohibición de una acción A determinada (cuya ejecución por parte de una persona se presume a partir de un hecho base) y, por la otra, la prohibición de continuar la indagación, una vez verificado el hecho base B. ${ }^{58} \mathrm{Como}$ contrapartida, se exigen dos acciones diferentes, a distintos agentes. Por una parte, se impone a la ciudadanía, el deber de no llevar a cabo la acción prohibida A (cuya ejecución se presumirá si se verifica el hecho base B) y, por la otra, se impone a quien debe decidir tener por probada, sin más, la ejecución de esa conducta prohibida $\mathrm{A}$ una vez verificado el hecho base B..$^{59}$

En breve,

a. se trata de normas que regulan conductas distintas: una se refiere a $\mathrm{A}$ y la otra se refiere a la aceptación de la proposición que afirma A como verdadera y a la continuación de la indagación, y

b. se trata de normas que se dirigen a destinatarios diferentes: una se dirige a la ciudadanía y la otra se dirige a quienes deben aplicar las normas dirigidas a la ciudadanía.

De ser esto así, las normas de PA ya no conciernen al "sistema primario o del súbdito", tal como el reduccionismo prentende, sino que son normas de obligación propias del "sistema del juez". ${ }^{60}$

No obstante, frente a todo este despliegue argumental, el reduccionista podría insistir concediendo que es posible trazar una distinción conceptual entre PA y las restantes normas, pero arguyendo que la distinción carece de relevancia práctica. Las consecuencias de reconstruir el sistema normativo de uno $u$ otro modo, podría aducir el defensor del reduccionismo, son exactamente iguales: el ciudadano o ciudadana que ejecute la acción B será castigado. En efecto, desde el reduccionismo hay quienes reconocen cierta peculiaridad a las normas de PA, pero subrayando que esa peculiaridad queda relegada al recóndito espacio de aquello que motiva la promulgación de ciertas normas, sin que los efectos jurídicos sean diversos en lo más mínimo para la ciudadanía:

Dicha distinción solo se mantiene en el plano interpretativo o explicativo de la ratio legis, esto es, en el nivel de la formación de la norma, sin que la verdad "presunta" o "ficticia" de un hecho determinado trascienda al contenido concreto de las normas que las establecen ni en los efectos jurídicos que producen. ${ }^{61}$

Llamemos a esta respuesta del reduccionismo "tesis de la identidad de consecuencias prácticas" (TIC). Asumiré en adelante que, si esta tesis es verdadera, entonces el esfuerzo hecho hasta aquí para distinguir las PA habrá sido en vano. Pero para evitar este desalentador desenlace intentaré a continuación refutar TIC haciendo explícitas las diferencias de optar por una $u$ otra reconstrucción del sistema normativo de referencia. Estas consecuencias se tornan evidentes si se presta atención al modo en que las presunciones pueden atacarse. 


\section{Bloquear, destruir y derrotar presunciones} estrategias, denominada bloqueo, consiste en la prueba de la falsedad del antecedente del condicional; es decir, la comprobación en cada caso de que no se ha dado el hecho base que hace operativa a la norma presuntiva. La segunda estrategia, denominada destrucción, consiste en la prueba de la falsedad del enunciado presumido aun en presencia del hecho base. ${ }^{62}$

$$
\begin{aligned}
& \text { iuris tantum, pues son ellas las únicas que admiten la invocación de la derrotabilidad } \\
& \text { empírica. En cambio, la (sola invocación de la estrategia de la) destrucción sería } \\
& \text { inadmisible frente a una PA, pues su rasgo principal -según se ha dicho- es el de ser } \\
& \text { inmunes a esta modalidad de ataque. }
\end{aligned}
$$

Esta última estrategia funcionaría, naturalmente, tan solo frente a las presunciones 
The presumption rule, though strictly speaking not rebuttable, is nevertheless revisable. ${ }^{65}$

Any presumption rule is revisable, even those relating to so-called "conclusive", or irrebuttable presumptions. ${ }^{66}$

La pregunta es, ¿cuál sería esa modalidad adicional de revisión? Recordemos que, de conformidad con el esquema de partida, si la garantía de un argumento es impugnada, es necesario justificarla acudiendo al respaldo. Supongamos que lo cuestionado frente a un argumento presuntivo iuris fuera la norma presuntiva, i.e. la garantía del argumento. $\mathrm{Al}$ igual que ante todo cuestionamiento de la garantía de un argumento sería necesario explicitar su respaldo y, eventualmente, incluso formular un argumento en favor de éste. Es precisamente aquí donde la justificación subyacente que hace peculiares a las normas de PA cobra relevancia práctica.

La tesis de la identidad de consecuencias prácticas que sostiene el reduccionismo presupone que las normas de PA no solo son inmunes a la estrategia de la destrucción, sino que lo son también a toda revisión ulterior. Esto es lo que parece pensar Schauer, para quien las PA no son más que reglas ordinarias. Unas u otras por igual

eliminan el acceso a sus justificaciones subyacentes... Una vez que vemos que las reglas tienen fuerza aun cuando dan lugar a resultados que no se darían mediante la aplicación de las razones o justificaciones subyacentes a ellas, podemos apreciar a las presunciones irrefutables en su mejor luz. ${ }^{67}$

Desde esta óptica, las normas jurídicas presuntivas hacen que los respaldos -las justificaciones subyacentes- queden atrincherados detrás de su juridicidad. ${ }^{68}$ Las razones subyacentes de la norma presuntiva devienen, de tal modo, absolutamente inexpugnables. Es esta la razón principal en virtud de la cual se afirma que reconstruir el sistema en términos de $\mathrm{S}_{1}$ o de $\mathrm{S}_{2}$ carece de relevancia práctica. Más aún, así planteada, la tesis de la identidad de consecuencias prácticas depende enteramente de esta asunción de inaccesibilidad a las razones subyacentes. Si esta tesis fuere correcta, aunque el reduccionista podría aceptar nuestra propuesta de conceptualización de las PA sobre la base de aquello que respalda las normas de PA, ${ }^{69}$ podría seguir insistiendo en que una conceptualización tal carece de relevancia práctica dado lo inaccesible de ese respaldo. ${ }^{70}$

70 El problema es que la tesis de la inaccesibilidad de las razones subyacentes es descriptivamente falsa, lo cual deja sin sustento aparente a la tesis de la identidad de las consecuencias prácticas y, así, al reduccionismo. En este sentido, las razones que subyacen a las normas jurídicas, al menos en el estado actual de nuestras prácticas, rara vez se consideran totalmente opacadas e inaccesibles. ${ }^{71}$ Esta cuestión se vincula con una serie de problemas de gran envergadura tanto para la teoría del derecho cuanto para la práctica jurídica en general. De hecho, si esos problemas cobran tanta importancia dentro de la teoría del derecho es porque están incrustados en la práctica decisoria judicial de nuestras culturas jurídicas. ${ }^{72}$ Piénsese no solo en lo relativo a la cuestión de las razones subyacentes y su revisión, ${ }^{73}$ sino en otras cuestiones íntimamente vinculadas con ella, tales como la relativa a las lagunas axiológicas, ${ }^{74}$ la llamada derrotabilidad normativa (en sus diversas variantes), ${ }^{75}$ la ponderación de principios, ${ }^{76}$ la cuestión de las excepciones implícitas, etc.

71 Estas cuestiones no pueden ser más que mencionadas en esta sede. Basta ahora con la siguiente consideración: nuestros ordenamientos jurídicos son generalmente concebidos como conteniendo distintos niveles jerárquicos de estándares normativos: reglas y principios. ${ }^{77}$ Es un lugar común el de asumir que en los estratos más altos del 
ordenamiento hay al menos algunos estándares normativos que delimitan el contenido de otras normas de inferior jerarquía. ${ }^{78}$ Algunos de estos estándares normativos, los que ahora me interesa resaltar, introducen al ordenamiento y tutelan valores juzgados como fundamentales. Ante esto, se encuentra ampliamente aceptada la idea según la cual algunos de esos estándares son principios cuyo aparente y eventual contraste debe ser resuelto por medio de ese modo especial de reflexión/argumentación denominado ponderación. Ello así en virtud de que, a diferencia de las reglas, los principios poseen una dimensión de peso que impide que ellos proporcionen soluciones a todo o nada. ${ }^{79}$ Por su parte, cuando una norma inferior del ordenamiento contrasta con un principio constitucional o cuando lo afecta de un modo no admitido a la luz de la ponderación que se lleve a cabo, esa norma se torna inválida, constitucionalmente ilegítima. Frente a ilegitimidades semejantes, aun cuando hay un gran debate acerca de la conveniencia o no de proceder de este modo, suele reconocerse a las cortes el poder de anular las normas contrastantes con esos principios fundamentales.

Por su parte, los materiales jurídicos que fungen de fuentes del derecho pueden ser interpretados de distintos modos dando lugar, consecuentemente, a sistemas normativos alternativos a los efectos de resolver las disputas. ${ }^{80}$ Así, al tiempo que algunas interpretaciones podrían conducir a sistemas admisibles frente a esos principios fundamentales $\mathrm{y}$ a las ponderaciones a llevar a cabo entre ellos, otras podrían ser inadmisibles conduciendo - entre otras cosas - a normas inválidas. ${ }^{81}$ De este modo, si las interpretaciones posibles condujesen todas a normas inconstitucionales, podría decirse que la inconstitucionalidad afecta a las disposiciones; pero si fueren admisibles ciertas interpretaciones acordes a la constitución de que se trate, entonces solo serían inconstitucionales ciertas interpretaciones y no otras, ciertas normas y no otras. ${ }^{82}$

73 A pesar de que se trata de una caracterización inevitablemente apresurada de la situación, ella es suficiente para mostrar que las razones subyacentes, los respaldos que justifican normas jurídicas, son determinantes a efectos de reconstruir los sistemas normativos sobre la base de los cuales resolver controversias. Rara vez, quizás nunca, esas razones son completamente opacas a estos efectos. Es en este sentido, que la tesis de la identidad de consecuencias prácticas propia del reduccionismo se basa en una asunción descriptivamente falsa: sencillamente no es verdad que las razones subyacentes sean tratadas como inexpugnables en la práctica; de hecho, no lo son.

En el caso de las presunciones iuris (cualquiera sea la variante de ellas), estas cuestiones cobran un tinte especial. Esto es así, por lo menos, en aquellos ordenamientos -o en relación con ciertos espacios o materias relativos a esos ordenamientos- que consagran un derecho a la prueba. Se asume muchas veces que un derecho tal deriva del más general derecho de defensa y que, por su parte, implica otros derechos más específicos. Entre ellos, por ejemplo, el derecho a utilizar, invocar o aportar todas las pruebas disponibles; el derecho a que ellas sean producidas y el derecho a que sean valoradas a la luz del sistema de 'prueba libre' o sana crítica racional. ${ }^{83}$ Ante esto, ha de recordarse que, como se dijo oportunamente, las presunciones iuris son "sucedáneos" de la prueba, son excepciones a ese derecho más fundamental. De modo que, en cuanto excepción, la validez de una presunción iuris dependerá siempre de las razones subyacentes que las sustenten, de que esas razones prevalezcan por sobre los principios que, por su parte, sustentan el derecho a la prueba. 

resultase perfectamente legítimo. Pues podría haber buenas razones para establecer una norma adicional a $\mathrm{N}_{1}$ (la norma que castiga $\mathrm{A}$ ), según la cual $\left(\mathrm{N}_{2}\right)$ : siempre que se dé $\mathrm{B}$, debe de tenerse por probado A sin posibilidad de prueba en contrario. Los estándares normativos superiores del ordenamiento bien podrían ser compatibles con una PA de A toda vez que $B$, pero no con castigar $B$. Aun cuando algún principio $P_{1}$ de $O J_{1}$ pudiera llegar a garantizar a la ciudadanía cierta autonomía para decidir si hacer o no hacer $\mathrm{B}$ de un modo prevaleciente sobre $\mathrm{P}_{2}$; ese principio $\mathrm{P}_{1}$ podría ceder si fuera el caso que (a) $B$ fuera una razón para creer que A, i.e. un indicio de A al tiempo que (b) otro principio $\mathrm{P}_{3}$ (o un conjunto de principios) resultase ponderativamente más fuerte que $\mathrm{P}_{1}$, 
justificando (no punir B pero sí) omitir seguir indagando si A es o no el caso ante la verificación del indicio $B$.

81 En este sentido, los valores que podrían verse afectados por la ejecución de la acción $\mathrm{B}$ (por caso, aquellos que vendría a proteger $\mathrm{P}_{2}$ ) no tienen por qué coincidir con los valores que podrían verse afectados por la indagación acerca de si A ha ocurrido o no en los casos en que también aconteció $\mathrm{B}$ (valores que vendría a proteger $\mathrm{P}_{3}$ ). Suponiendo que todos los valores en juego están constitucionalmente protegidos, la situación que quiero enfatizar sería la siguiente: $\mathrm{P}_{1}$ prevalece ante $\mathrm{P}_{2}$, de modo que la interpretación reduccionista se torna ilegítima al conducir a una norma prohibitiva inconstitucional (i.e. $\mathrm{N}_{3}$ ); pero $\mathrm{P}_{1}$ cede ante $\mathrm{P}_{3}$, de modo que la interpretación en términos de PA es legítima. Entender nuestras disposiciones $\mathrm{D}_{1}$ y $\mathrm{D}_{2}$ en los términos de $\mathrm{S}_{1}$ no solo hallaría en el sistema una auténtica PA sino que, además, proporcionaría una norma válida $\mathrm{o}$, mejor dicho, evitaría inferir una norma inválida como $\mathrm{N}_{3}$. He aquí una diferencia práctica crucial entre uno $\mathrm{u}$ otro tipo de interpretación. ${ }^{84}$ Distinguir las PA como genuinos casos de presunción sin posibilidad de prueba en contrario permite ver estos matices y amplía notablemente las alternativas argumentales de quienes participan en la práctica jurídica.

82 En este sentido, lo antes dicho muestra claramente cuáles son las alternativas argumentales de quienes configuran el sistema normativo a emplear para resolver disputas, lo que incluye al menos a las legislaturas y a las judicaturas. Como se vio, desde esas ópticas hay al menos dos alternativas para configurar ese sistema normativo; alternativas que además de ser independientes en términos conceptuales, lo son también desde el punto de vista justificativo. Pero el hecho de que la autoridad cuente con esas alternativas no debe oscurecer que ellas amplían también el campo argumental de los justiciables.

83 Ya hemos visto que, frente a un sistema reconstruido en los términos de $\mathrm{S}_{2}$, el justiciable podría impugnar la validez de una norma como $\mathrm{N}_{3}$, por ejemplo, porque ciertos principios $\mathrm{P}_{1}$ impiden sancionar la conducta $\mathrm{B}$, dejándola librada a su autonomía de la voluntad. Frente a esto, hemos visto que en un ordenamiento tal podría ser el caso que interpretar las disposiciones pertinentes como expresiones de una genuina PA (y no una norma como $\mathrm{N}_{3}$ ) podría resultar perfectamente legítimo.

Pues bien, aunque esta alternativa amplía efectivamente las posibilidades justificativas desde la óptica de la autoridad, ella posee una contracara, a saber: pone a disposición de los justiciables la posibilidad de impugnar la PA misma, apelando a dos circunstancias adicionales que el reduccionista no logra captar. En efecto, $\mathrm{N}_{2}$ podría ser atacada (a) impugnando la relevancia epistémica de $\mathrm{B}$ respecto de A, i.e. negando que el hecho básico aumente la probabilidad epistémica del hecho presumido; y (b) impugnando las razones (los principios, la ponderación, etc.) que informan la obstrucción probatoria, i.e. las que justifican prohibir seguir indagando si A fue o no efectivamente el caso toda vez que se haya verificado $B$.

\section{Conclusión}

85 Lleva razón el reduccionista en que una PA parece conducir, en la práctica, a que se condene a la persona que ejecute una acción presentada como hecho base (e.g. B) del mismo modo en que es condenado quien ejecuta la acción que oficia de enunciado 
presumido (e.g. A). Pero ello es así, no porque la acción que opera como hecho base esté prohibida del mismo modo en que lo está la presumida, sino porque se juzga justificado, a la luz de la constatación de la primera,

i. tener por probado que también se llevó a cabo la acción presumida (en el ejemplo, A), en virtud de la fuerza que B tiene como razón epistémica en favor de A, y

ii. bloquear toda indagación ulterior acerca de si A ha sido o no el caso, en virtud de la fuerza que ciertos estándares normativos tienen como razones prácticas en tutela de ciertos valores que podrían verse afectados por la continuación o profundización de la actividad probatoria.

Por cierto, quizás esta específica y singular configuración normativa a la cual hemos propuesto reconducir a la noción de PA no esté justificada jamás a la luz de ciertos valores y de ciertos postulados asumidos como fundamentales en los ordenamientos jurídicos. ${ }^{85} \mathrm{O}$ quizás las PA no estén justificadas dentro de un cierto sector del ordenamiento, o respecto de una cierta materia, o en relación con cierto tipo de casos. Pero empeñarse en estas reflexiones justificativas presupone comprender cabalmente en qué consisten esas presunciones, pues el tipo de justificación que ellas requieren no solo las dota de autonomía conceptual, sino de una enorme potencialidad práctica.

-Agradecimientos. - Este texto fue discutido el 24 de mayo de 2019 en el Permanent Workshop del Lisbon Legal Theory Group. Agradezco a quienes participaron en dicho seminario por sus valiosos comentarios y sugerencias. Josep Aguiló Regla, Edgar Aguilera García, Pierluigi Chiassoni, Miguel Fernández Núnez, Jordi Ferrer Beltrán, Daniel González Lagier, Santiago Sánchez Gavier, Carmen Vázquez han leído versiones preliminares de este manuscrito; sus objeciones y sugerencias fueron de gran valor y motivaron gran cantidad de cambios respecto de esos primeros borradores. Agradezco también por sus comentarios a dos dictaminadoras/es anónimas/os.

\section{BIBLIOGRAPHY}

Ackerman, B. L. (1977). The Conclusive Presumption Shuffle. University of Pennsylvania Law Review, 125(4), 761-810. doi: 10.2307/3311519.

Aguiló Regla, J. (2006). Presunciones, verdad y normas procesales. Isegoría, 35, 9-31

Aguiló Regla, J. (2017). Las presunciones hominis y las inferencias probatorias. Revista de la Facultad de Derecho PUCP, 79, 99-110.

Aguiló Regla, J. (2018). Las presunciones en el Derecho. Anuario de Filosofía del Derecho, XXXIV, 201-228.

Aguiló-Regla, J. (2005). On Presumptios and Legal Argumentation. Logic, Argumentation and Interpretation: proceedings of the 22nd IVR World Congress, V, 167-174.

Alchourron, C. E. (2000 [1996]). Sobre derecho y lógica. Isonomía, 13, 11-33.

Alchourrón, C. E., \& Bulygin, E. (1983). Definiciones y normas. In E. Bulygin, M. Farrel, D., C. S. Nino, \& E. Rabossi (Eds.), El lenguaje del Derecho. Homenaje a Genaro R. Carrió. Buenos Aires: AbeledoPerrot. 
Alchourrón, C. E., \& Bulygin, E. (2006 [1971]). Introducción a la metodología de las ciencias jurídicas y sociales. Buenos Aires: Astrea.

Alexy, R. (1994). El concepto y la validez del Derecho (1ed.). Barcelona: Gedisa.

Alexy, R. (2008). Teoría de los derechos fundamentales (2da. ed.). Madrid: Centro de Estudios Políticos y Constitucionales.

Allen, R. J. (1981). Presumptions in Civil Actions Reconsidered. Iowa Law Review, 66, 843-897.

Allen, R. J. (1982). Presumptions, Inferences and Burden of Proof in Federal Civil Actions - An Anatomy of Unnecessary Ambiguity and a Proposal for Reform. Northwestern University Law Review, 76(6), 892-911.

Atienza, M. (1991). Las razones del derecho. Teorías de la argumentación jurídica. Madrid: Centro de Estudios Constitucionales.

Atienza, M. (2005). El derecho como argumentación concepciones de la argumentación. Mexico D.F.: Distribuciones Fontamara.

Atienza, M. (2010). A vueltas con la ponderación. Anales de la Cátedra Francisco Suárez(44), 43-59.

Atienza, M., \& Ruiz Manero, J. (1996). Las piezas del derecho. Teoría de los enunciados jurídicos. Barcelona: Ariel.

Bayón Mohino, J. C. (2000). Derrotabilidad, indeterminación del derecho y positivismo jurídico. Isonomía, 13, 87-117.

Bayón Mohino, J. C. (2008). Epistemología, moral y prueba de los hechos: hacia un enfoque no benthamiano. Paper presented at the XIV Congreso ítalo-español de teoría del derecho, Girona. http://www.udg.edu.

Bayón Mohino, J. C. (2009). Epistemología, moral y prueba de los hechos: hacia un enfoque no benthamiano. Analisi e diritto. Ricerche di giurisprudenza analitica, 2009-2010(1), 15-34.

Bayón Mohíno, J. C. (1996). Principios y reglas: legislación y jurisdicción en el Estado constitucional. Jueces para la Democracia, 47, 41-49.

Best, W. M. (1845). A treatise on Presumptions of Law and Fact with the Theory and Rules of Presumptive or Circumstantial Proof in Criminal Cases. In (pp. xxxviii, 391 p.).

Bouvier, H. (2004). Reglas y razones subyacentes. Doxa: cuadernos de filosofía del derecho, 27, 393-424.

Bulygin, E. (1991 [1985]). Normas y lógica. Kelsen y Weinberger sobre la ontología de las normas. In Análisis lógico y derecho (pp. 249-265). Madrid: Centro de Estudios Constitucionales.

Carrió, A. (2005). Excarcelaciones, presunción de inocencia, peligro de fuga y peligrosidad. Revista de Derecho Procesal Penal: excarcelación, 69-82.

Celano, B. (2002). "Defeasibility" e bilanciamento. Sulla possibilità di revisioni stabili. Diritto \& questioni pubbliche, 2, 34-46.

Celano, B. (2006). Principi, regole, autorità. Europa e diritto privato, 3, 1061-1086.

Chiassoni, P. (2019a). El problema del significado jurídico. México: Fontamara (en prensa).

Chiassoni, P. (2019b). Interpretation without Truth. A Realistic Enquiry. New York: Springer.

Cohen, L. J. (1995). An Essay on belief and acceptance. Oxford: Clarendon Press. 
Comanducci, P. (1987). Osservazioni in margine. In P. Comanducci \& R. Guastini (Eds.), L'Analisi del ragionamento giuridico: materiali and degli studenti (pp. 265-275). Torino: G. Giappichelli.

Comanducci, P. (1992). La motivazione in fatto. In G. Ubertis, (et al.) (Ed.), La conoscenza del fatto nel processo penale (pp. 215-244). Milano: Giuffrè.

Couture, E. J. (1958). Fundamentos de Derecho Procesal Civil (3º ed.). Buenos Aires: Depalma.

Dan-Cohen, M. (1984). Decision Rules and Conduct Rules: On Acoustic Separation in Criminal Law. Harvard Law Review, 97(3), 625-677. doi: 10.2307/1340892.

Darwall, S. (2006). The Second-Person Standpoint: Morality, Respect, and Accountability. Cambridge Massachusetts - London: Harvard University Press.

Davidson, D. (2001 [1983]). A Coherence Theory of Truth and Knowledge. In Subjective, Intersubjective, Objective (pp. 137-158). Oxford-New York: Clarendon Press-Oxford University Press.

Duff, A. (2007). Answering for Crime: Responsibility and Liability in the Criminal Law. In Legal theory today.

Dworkin, R. (1986). Law's Empire. Cambridge - Massachusetts: Belknap Press of Harvard University Press.

Dworkin, R. (2013 [1977]). Taking Rights Seriously. London - New Delhi - New York - Sidney: Bloomsbury Publishing.

Dworkin, R. M. (1967). The Model of Rules. The University of Chicago Law Review, 35(1), 14-46. doi: $10.2307 / 1598947$.

Fabbrini, G. (1996). Presunzioni. Digesto delle discipline privatistiche, Sezione Civile, XIV, 279-293.

Fernández López, M. (2005). Prueba y presunción de inocencia (1* ed ed.). Madrid: Iustel.

Ferrer Beltrán, J. (2001). ‘Está probado que p’. In L. Triolo (Ed.), Prassi giuridica e controllo di razionalità (Vol. I, pp. 73-96). Torino: G. Giappichelli.

Ferrer Beltrán, J. (2005). Prueba y verdad en el derecho (2da. ed.). Madrid Barcelona: Marcial Pons.

Ferrer Beltrán, J. (2006). Legal proof and fact finders' beliefs. Legal Theory, 12(4), 293-314.

Ferrer Beltrán, J. (2007). La valoración racional de la prueba. Madrid: Marcial Pons.

Ferrer Beltrán, J. (2010). Una concepción minimalista y garantista de la presunción de inocencia. Revista de la Maestría en Derecho Procesal (PUCP), 4(1).

Ferrer Beltrán, J. (2013). La prueba es libertad, pero no tanto: una teoría de la prueba cuasibenthamiana. In C. Vázquez (Ed.), Estándares de prueba y prueba científica (pp. 21-39). Madrid Barcelona - Buenos Aires - Sao Paulo: Marcial Pons.

Ferrer Beltrán, J., \& Ratti, G. B. (2012). The Logic of Legal Requirements. Essays on Defeasibility. Oxford: Oxford University Press.

Fuller, L. L. (1967). Legal fictions. Stanford, Calif: Stanford University Press.

Fuller, L. L. (2006 [1967]). ¿Qué es una ficción jurídica? In H. Kelsen, L. F. Fuller, \& A. Ross (Eds.), Ficciones jurídicas (1* ed., pp. 57-103). México: Fontamara.

Gama Leyva, R. (2013). Concepciones y tipología de las presunciones en el derecho continental. Revista de Estudios de la Justicia, 19, 65-89. 
Gama Leyva, R. (2015). Presumptions and Fictions: A Collingwoodian Approach. In M. Del Mar \& W. Twining (Eds.), Legal Fictions in Theory and Practice. New York: Springer.

Gama Leyva, R. (2019). Las presunciones en el Derecho. Entre la perplejidad y la fascinación de los juristas. Valencia: Tirant lo Blanch.

Garofoli, V. (2000). Presunzione d'innocenza e considerazione di non colpevolezza. La fungibilitá delle due formulazioni. In A.t. g. s. d. p. penale (Ed.), Presunzione di non colpevolezza e disciplina delle impugnazioni (pp. 63-104). Milano: Giuffrè.

Gascón Abellán, M. (2004). Los hechos en el derecho: Bases argumentales de la prueba (2da. ed.). Madrid- Barcelona: Marcial Pons.

Goldman, A. I. (1967). A Causal Theory of Knowing. Journal of Philosophy, 64(12).

Goldman, A. I. (1999). Knowledge in a Social World. Oxford: Clarendon Press.

González Lagier, D. (2007). Hechos y conceptos. Dialnet: cuadernos electrónicos de filosofía del derecho, 15.

González Lagier, D. (2013). Quaestio facti. Ensayos sobre prueba, causalidad y acción. México D.F.: Fontamara.

Green, S. P. (2005). Six Senses of Strict Liability: A Plea for Formalism. In A. P. Simester (Ed.), Appraising strict liability (pp. 1-21). Oxford: Oxford University Press.

Grevi, V. (2000). Presunzione di non colpevolezza, garanzie dell'imputato ed efficienza del processo nel sistema costituzionale. In A.t. g. s. d. p. penale (Ed.), Presunzione di non colpevolezza e disciplina delle impugnazioni (pp. 15-62). Milano: Giuffrè.

Guastini, R. (2004). L'interpretazione dei documenti normativi. Milano: Giuffrè.

Guastini, R. (2008). Nuovi studi sull'interpretazione. Roma: Aracne.

Guastini, R. (2010). Deffetibilita, lacune assiologiche e interpretazione. Revus - European Constitutionality Review, 14, 57-72.

Guastini, R. (2011). Interpretare e argomentare. Milano: Giuffrè.

Guastini, R. (2013a). Gerarchie normative. Revus, 21, 57-70.

Guastini, R. (2013b). Manifesto di una filosofia analitica del diritto. In R. Guastini (Ed.), Distinguendo ancora (pp. 13-26). Madrid - Barcelona - Buenos Aires - Sao Paolo: Marcial Pons.

Guastini, R. (2018). Filosofía del derecho positivo. Manual de teoría del Derecho en el Estado Constitucional. Lima: Palestra.

Haack, S. (2009). Evidence and Inquiry. A Pragmatist Reconstruction of Epistemology (2nd, expanded ed ed.). Amherst, N.Y.: Prometheus Books.

Hart, H. L. A. (2012). Postcript. In H. L. A. Hart (Ed.), The concept of law (3rd ed., pp. 238-276).

Oxford: Oxford University Press.

Illuminati, G. (1979). La presunzione d'innocenza dell'imputato. Bologna: Zanichelli.

Kelsen, H. (2006 [1919]). Reflexiones en torno de la teoría de las ficciones jurídicas: con especial énfasis en la filosofía “como si” de Vaihinger. In H. Kelsen, L. F. Fuller, \& A. Ross (Eds.), Ficciones jurídicas (1* ed., pp. 23-56). México: Fontamara.

Laporta, F. J. (2007). El imperio de la ley: una visión actual. Madrid: Trotta. 
Laudan, L. (2005). The Presumption of Innocence: Material or Probatory? Legal Theory(11), 333-361.

Laudan, L. (2006). Truth, Error, and Criminal Law: An Essay in Legal Epistemilogy (1st ed.). Cambridge: Cambridge University Press.

Macagno, F., \& Walton, D. (2012). Presumptions in Legal Argumentation. Ratio Juris, 25(3), 271-300. doi: 10.1111/j.1467-9337.2012.00514.x.

Maniaci, G. (2002). Note sulla teoria del bilanciamento di Robert Alexy. Diritto \& questioni pubbliche, 2, 47-73.

Martínez Zorrilla, D. (2007). Conflictos constitucionales, ponderación e indeterminación normativa. Madrid: Marcial Pons.

McBaine, J. P. (1938). Presumptions; Are They Evidence? California Law Review, 26(5), 519-563. doi: $10.2307 / 3476598$.

Mendonca, D. (1998). Presunciones. Doxa: Cuadernos de Filosofía del Derecho, 21, 83-98.

Mendonca, D. (1999). Presumptions. Ratio Juris, 11(4), 399-412. doi: 10.1111/1467-9337.00098.

Mendonca, D. (2006). Estudio preliminar. In H. Kelsen, L. F. Fuller, \& A. Ross (Eds.), Ficciones jurídicas (1* ed., pp. 7-22). México: Fontamara.

Montmarquet, J. A. (2007). “Pure” versus "Practical” Epistemic Justification. Metaphilosophy, 38(1), 71-87.

Moreso, J. J. (2002). Conflitti tra princìpi costituzionali. Diritto \& questioni pubbliche, 2, 19-34.

Moreso, J. J. (2006). Ferrajoli sui confitti tra diritti. Diritto \& questioni pubbliche, 6, 133-141.

Moreso, J. J. (2007). Alexy y la aritmética de la ponderación. In R. Alexy \& R. García Márquez (Eds.), Derechos sociales y ponderación. Madrid: Fundación Coloquio Jurídico Europeo.

Moreso, J. J. (2017). Villa sobre los desacuerdos interpretativos. ¿Pueden ser genuinos y sin culpa? Diritto \& Questioni Pubbliche, XVII(2), 325-344.

Morgan, E. M. (1931). Some Observations concerning Presumptions. Harvard Law Review, 44(6), 906-934. doi: 10.2307/1332260.

Morgan, E. M. (1937). Presumptions. Washington Law Review, 12(4), 255-281.

Navarro, P., \& Jorge, R. (2000). Derrotabilidad y sistematización de normas jurídicas. Isonomía, 13, 61-85.

Navarro, P. E., \& Rodríguez, J. (2000). Derrotabilidad y sistematización de normas jurídicas. Isonomía(13), 61-85.

Nino, C. S. (2005). Fundamentos de derecho constitucional: Análisis filosófico, jurídico y politológico de la práctica constitucional. Buenos Aires: Astrea.

Olshausen, G. G. (1943). Evidence: Presumptions as Evidence--A Reply. California Law Review, 31, 316-325.

Parret, H. (1993). The Aesthetics of Communication. Dordrecht: Springer.

Paulesu, P. P. (2009). La presunzione di non colpevolezza dell'imputato (Vol. 30). Torino: G. Giappichelli.

Peirce, C. S. (1931). Collected papers of Charles Sanders Peirce. Cambridge: Harvard University Press. 
Picinali, F. (2014). Innocence and burdens of proof in English criminal law. Law, Probability and Risk, 13(3-4), 243-257. doi: 10.1093/lpr/mgu007.

Pino, G. (2009). Principi e argomentazione giuridica. Ars Interpretandi. Rivista di ermeneutica giuridica(14), 131-160.

Pizzi, C. (1992). Oggettività e relativismo nella ricostruzione del fatto: riflessioni logicofilosofiche. In G. Ubertis, (et al.) (Ed.), La conoscenza del fatto nel processo penale (pp. 195-213). Milano: Giuffrè.

Plaxton, M. (2010). Offence Definitions, Conclusive Presumptions, and Slot Machines Osgoode Hall Law Journal, 48(1), 145-173.

Prakken, H. (1997). Logical Tools for Modelling Legal Argument. A Study of Defeasible Reasoning in Law. Dordrecht London: Kluwer Academic Publishers.

Prieto Sanchís, L. (2003). El juicio de ponderación constitucional. In F. J. Laporta (Ed.), Constitución: Problemas filosóficos. Madrid: Centro de Estudios Constitucionales.

Quinn, M. (2013). Fuller on Legal Fictions: A Benthamic Perspective. nternational Journal of Law in Context, 9(4), 466-484. doi: doi:http://dx.doi.org/10.1017/S1744552313000256.

Roberts, P. (2005). Strict Liability and the Presumption of Innocence: An Exposé of Functionalist Assumptions. In A. P. Simester (Ed.), Appraising strict liability (pp. 152-195). Oxford: Oxford University Press.

Roberts, P. (2014). Loss of Innocence in Common Law Presumptions. Criminal Law and Philosophy, $8(2)$.

Roberts, P., \& Zuckerman, A. A. S. (2004). Criminal Evidence. Oxford - New York: Oxford University Press.

Rodríguez, J. L. (2002). La lógica de los sistemas juridicos. Madrid: Centro de Estudios Políticos y Constitucionales.

Rodríguez, J. L., \& Sucar, G. (1998). Las trampas de la derrotabilidad. Niveles de análisis de la indeterminación del derecho. Doxa: cuadernos de filosofía del derecho, 21 vol. II, 403-420.

Roland Matida, J. (2019). Em defesa de um conceito jurídico de presunção. (PhD), Universitat de Girona, Girona.

Ross, A. (2006). Ficciones jurídicas. In H. Kelsen, L. F. Fuller, \& A. Ross (Eds.), Ficciones jurídicas (1* ed., pp. 105-124). México: Fontamara.

Santibáñez, C. (2011). Presunción (voz). In L. Vega \& P. Olmos Gómez (Eds.), Compendio de lógica, argumentación y retórica (pp. 481-483). Madrid: Trotta.

Schauer, F. (1988). Formalism. Yale Law Journal, 97(4), 509-548.

Schauer, F. (2013). Pensar como un abogado: una nueva introducción al razonamiento jurídico. Madrid [etc.]: Marcial Pons.

Schauer, F. (2015). Legal Fictions Revisited. In W. Twining \& M. Del Mar (Eds.), Legal Fictions in Theory and Practice: Springer Verlag.

Schauer, F. F. (1991). Playing by the Rules. A Philosophical Examination of Rule-Based Decision-Making in Law and in Life. Oxford: University Press.

Schroeder, M. (2018). The Unity of Reasons. In D. Star (Ed.), The Oxford handbook of reasons and normativity (pp. 46-66). Oxford: Oxford University Press. 
Scurich, N., Nguyen, K. D., \& John, R. S. (2015). Quantifying the presumption of innocence. Law, Probability and Risk, 15(1), 71-86. doi: 10.1093/lpr/mgv016.

Sentís Melendo, S. (1979). La Prueba: los grandes temas del derecho probatorio. Buenos Aires: Ediciones Jurídicas Europa-América.

Serra Domínguez, M. (1963). Normas de presunción en el codigo civil y ley de arrendamientos urbanos. Barcelona: Nauta.

Strahovnik, V. (2016). Defeasibility, norms and exceptions: normalcy model. Revus, 29, 61-76.

Strawson, P. F. (1995 [1968]). Libertad y resentimiento. In P. F. Strawson (Ed.), Libertady resentimiento. $Y$ otros ensayos (pp. 37-67). Barcelona: Paidós.

Stumer, A. C. (2018). La presunción de inocencia. Perspectiva desde el Derecho probatorio y los derechos humanos. Madrid: Marcial Pons.

Tarello, G. (1980). L' Interpretaziones della legge (V. I t. 2 ed.). Milano: Giuffré.

Taruffo, M. (1974). Certezza e probabilità nelle presunzioni. Il Foro Italiano, 97, 83/84-111/112.

Taruffo, M. (1991). Presunzioni (diritto processuale civile). In Enciclopedia Giuridica (pp. 1-5). Roma: Treccani.

Tomlin, P. (2014). Could the Presumption of Innocence Protect the Guilty? Criminal Law and Philosophy, 8(2). doi: DOI: 10.1007/s11572-012-9193-6.

Toulmin, S. (1975). Gli usi dell'argomentazione (1a. ed.). Torino: Rosenberg and Sellier.

Toulmin, S. (2003 [1958]). The Uses of Argument (Updated ed.). Cambridge: Cambridge University Press.

Tuzet, G. (2011). Una teoria coerentista delle finzioni. Ragion pratica, 2011(2), 529-552. doi: $10.1415 / 35683$.

Ullman-Margalit, E. (1983). On Presumption. The Journal of Philosophy, 80(3), 143-163.

Vázquez Sotelo, J. L. (1984). Presunción de inocencia del imputado e íntima convicción del tribunal : estudio sobre la utilización del imputado como fuente de prueba en el proceso penal español. Barcelona: Bosch.

Walton, D. N. (2005). Abductive reasoning. Tuscaloosa: University of Alabama Press.

Wigmore, J. H. (1923). A Treatise on the Anglo-American System of Evidence in Trials at Common Law: including the Statutes and Judicial Decisions of all Jurisdictions of the United States and Canada (2nd ed.). Boston: Little, Brown.

Wróblewski, J. (1967). Il modello teorico dell'applicazione della legge. Rivista internazionale di Filosofia del Diritto, 46, 10-30.

Wróblewski, J. (1974). Legal Syllogism and Rationality of Judicial Decision. Rechtstheorie, 5, 33-46.

\section{NOTES}

1. Es indispensable tener presente que, como se verá oportunamente, de disposiciones como estas se extraen normas presuntivas. La presencia de una norma presuntiva de carácter absoluto, i.e. iuris et de iure, no supone necesariamente el empleo de la expresión iuris et de iure en la disposición de la cual se la extrae. Por el contrario, la presencia de una norma tal dependerá de 
que se den ciertas características propias de la justificación subyacente de esa norma. A la elucidación de esas características se dedica este texto.

2. A un punto tal que se ha abogado por su total supresión: Allen 1981, Allen 1982.

3. RAE: https://dle.rae.es/?id=U7YygFe. Las mismas acepciones se dan en muchas de las demás lenguas romances. En idioma inglés la situación es semejante. La acepción que ahora se está tomando como central está definida del siguiente modo en el OED: "the action of taking for granted or presuming something; assumption, expectation, supposition; an instance of this; a belief based on available evidence".

4. Sobre la noción de razones del tipo adecuado y del tipo inadecuado, véanse Strawson 1995 [1968] y Darwall 2006. El hecho de que las razones adecuadas para aceptar proposiciones como verdaderas son las de índole epistémica debe tomarse con precaución. Las razones epistémicas son las únicas que 'indican' la verdad de las proposiciones (Haack 2009, especialmente cap. 9) o que 'generan' creencias verdaderas (Goldman 1967, Goldman 1999), según la concepción que se tenga de la epistemología. De allí que se trate de razones prioritarias. Pero esto no quiere decir que las razones prácticas no tengan relevancia en la aceptación de ciertas proposiciones qua verdaderas. De hecho, creo que las razones prácticas son necesarias a estos efectos. Esta cuestión no puede ser tratada en este marco, aunque algo se dirá más adelante. Sobre el punto puede verse Montmarquet 2007.

5. En este sentido amplio, naturalmente, queda incluida la 'presunción de inocencia', en virtud de la cual -al menos en algunas de sus formulaciones- ninguna persona puede ser tenida por culpable, o tratada como culpable, etc., antes de que su culpabilidad haya sido probada. De allí que muchas veces se diga que el instituto opera como una 'verdad interina'. No puedo detenerme aquí en esta compleja cuestión, solo me interesa resaltar que ella está vinculada estrechamente con la aceptación (o no) de ciertos enunciados fácticos qua verdaderos. Véanse Illuminati 1979, Vázquez Sotelo 1984, Garofoli 2000, Grevi 2000, Carrió 2005, Fernández López 2005, Laudan 2005, Paulesu 2009, Ferrer Beltrán 2010, Picinali 2014, Roberts 2014, Tomlin 2014, Scurich, Nguyen \& John 2015, Stumer 2018.

6. En este último sentido, las cosas podrían complejizarse todavía más, ya que 'presunción' puede aludir a la asunción en términos de lo que Bertrand Russell bautizó actitud proposicional o bien en términos de lo que J. L. Austin llamó acto ilocucionario. Véase la presentación general de Santibáñez 2011. Además, si bien he identificado al proceso con una operación argumental, lo cierto es que este también podría ser entendido y estudiado como operación psicológica. Esas operaciones no son necesariamente homogéneas: véase sobre este problema, aludiendo a la decisión judicial, Wróblewski 1974, Comanducci 1987, Comanducci 1992. De allí que, podría decirse, la ambigüedad proceso-producto del término 'presunción' es doble: el término puede aludir tanto a la actividad psicológica y su resultado cuanto a la actividad lingüístico-argumental y su resultado.

7. Macagno \& Walton 2012 sostienen que las presunciones deben ser analizadas en dos niveles: el inferencial, en el sentido que aquí se le ha dado, y el dialéctico, a cuya luz las presunciones son actos de habla.

8. Véase a Toulmin 2003 [1958], cap. III Emplean esta herramienta, por ejemplo, Atienza 1991: 107, Aguiló-Regla 2005, Aguiló Regla 2006, González Lagier 2013, cap. II, Aguiló Regla 2018.

9. Toulmin 1975: 92.

10. González Lagier 2013: 41, quien está aquí llamando 'presunciones' a ciertas normas que se distinguirán en breve como normas presuntivas. Véase también Gascón Abellán 2004: 151-152.

11. Toulmin 2003 [1958]: 95 y ss..

12. Además de condecirse con el significado ordinario del vocablo, la estipulación se corresponde en buena medida con la terminología utilizada por los juristas en relación con la 'prueba indirecta'. Cfr. Pizzi 1992.

13. Gascón Abellán 2004: 152-153. 
14. Véase el mismo uso del vocablo en The Five Orange Pips.

15. Véanse, en el ámbito filosófico, Peirce 1931, 2.430, 2.756, 2.774, 2.776 En este último parágrafo dice: "Presumption, or, more precisely, abduction (which the present writer believes to have been what Aristotle's twenty-fifth chapter of the second Prior Analytics imperfectly described under the name of \{apagögé\}, until Apellicon substituted a single wrong word and thus disturbed the sense of the whole), furnishes the reasoner with the problematic theory which induction verifies". Véanse también Mcbaine 1938: 525 y ss., Olshausen 1943: 320-321, Parret 1993: 68 y ss., Walton 2005: 26-31, Haack 2009: 61, Macagno \& Walton 2012: 281. Taruffo 1974, Taruffo 1991 parece incluso sugerir que el término 'presunción' habría de reservarse en esta acepción, negándole carácter presuntivo a las llamadas 'presunciones legales'. Por el contrario, hay quienes son reacios a llamar 'presunciones' a las 'presunciones hominis' o 'naturales': véase Wigmore 1923, $\$ 2491$ (en la misma orientación Roberts 2014: 321). En todo caso, aun cuando Wigmore en efecto renegaba del empleo del término para designar a las 'presunciones hominis' no solo no desconoce la existencia de las dos clases de argumento aquí diferenciadas, sino que los criterios de distinción parecen ser los mismos que ahora empleamos. La conveniencia o no del uso del término 'presunción' para referir a las llamadas 'presunciones hominis' no es algo que me interese discutir aquí. Ello por dos razones: por una parte, porque negar esa acepción choca con el ya acreditado uso generalizado del vocablo como sinónimo de las inferencias probatorias; por la otra parte, y en gran medida en virtud de lo anterior, porque la discusión me parece del todo irrelevante. Lo importante es distinguir los distintos conceptos que un mismo término ambiguo expresa para evitar confundirlos, no extirparle al término su capacidad para expresar más de un concepto.

16. Sobre los distintos grados de fortaleza de estas presunciones, véase la clasificación que proponen Macagno \& Walton 2012: 284-285. Sobre la derrotabilidad de este tipo de argumentos véase Prakken 1997.

17. Empleo la expresión 'hecho base' dado que es la que se ha establecido como terminología canónica en la discusión sobre presunciones. Debe destacarse, en cualquier caso, que lo que opera como razón del argumento en la presunción iuris (y también en la presunción hominis) no es un hecho sino más bien una proposición (i.e. el significado de un enunciado acerca de un hecho), un dato presuntivo. Para una profundización sobre esta cuestión véase la discusión desarrollada por Haack 2009, cap. III. La razón de fondo ha de buscarse en Davidson 2001 [1983].

18. Sobre la noción de aceptación y sobre el rol crucial que ellas juegan en las presunciones, véase Mendonca 1998, Mendonca 1999. Véase también Ferrer Beltrán 2001, Ferrer Beltrán 2006. Para un enfoque más general, véase Cohen 1995. Para algunas precisiones terminológicas relativas a la distinción entre presunciones hominis e iuris véanse Aguiló Regla 2005, Aguiló Regla 2006, Aguiló Regla 2017, Aguiló Regla 2018.

19. Sentís Melendo 1979: 242-243. Véase también Couture 1958: 227. Cfr. Stumer 2018: 32-34 quien, apartándose de las clasificaciones más asentadas en la dogmática penal y procesal penal, considera a las presunciones iuris casos especiales de presunción hominis (i.e. serían algo así como inferencias probatorias cuya una peculiaridad sería la de ser sugeridas, por ejemplo, por los jueces a los jurados populares), al tiempo que distingue entre presunciones iuris et de iure refutables (las que aquí se denominaron presunciones iuris) y presunciones iuris et de iure irrefutables.

20. Así: "the incorporation of presumptions by way of law is a mechanism generally used by the law in order to solve, in a certain way, cases in which there is uncertainty about whether or not certain circumstances related to certain solutions given by some norms of the respective system obtain" (Mendonca 1999: 409). Macagno \& Walton 2012 sostienen que una característica de todas las presunciones es la de operar en casos de ausencia 'de prueba', pero por 'prueba' están entendiendo aquí 'prueba suficiente'. Es decir, no es que se opere en ausencia de razones del tipo adecuado (i.e. pruebas, razones epistémicas) sino en ausencia de pruebas suficientes. 
21. Sobre la distinción "sistema del súbdito o primario" frente al "sistema del juez o secundario", véanse Bulygin 1991 [1985]: 263, Alchourrón \& Bulygin 2006 [1971].

22. Aunque el ser derrotable en este sentido no implica todavía, por cierto, que a la presunción iuris subyazca una presunción hominis lo cual es, veremos, contingente.

23. Véase Gascón Abellán 2004: 139-141.

24. Best 1845: 34-35.

25. Véase González Lagier 2007.

26. Esto es así tanto en relación con las presunciones hominis cuanto respecto de las presunciones iuris. Soy consciente, en cualquier caso, de que no todas las presunciones iuris presuponen sustento empírico (máximas de experiencia, etc.), al menos no necesariamente, de allí que el tipo de razones cuya suficiencia consagran para la aceptación del enunciado presumido puedan considerarse no adecuadas desde el punto de vista epistémico. En este sentido, las presunciones operan justificando la aceptación de ciertos enunciados fácticos, pero esa justificación cambia de índole de uno a otro tipo de presunción.

27. Aguiló Regla 2018: 221-222.

28. Véanse Aguiló Regla 2006: 25-26, Aguiló Regla 2018: 223. Aunque el ejemplo figura también en Schauer 2013: 230, lo cierto es que él no parece entenderlo como un ejemplo de PA, sino que toma el caso como instancia de una regla ordinaria a ser comparada con las (supuestas) PA, pero ello así, precisamente, para mostrar la ausencia de una diferencia relevante. Para Gama Leyva (2019), en esta orientación, las presunciones absolutas no son más que "normas basadas en presunciones. En estas últimas la presunción se presenta en el ámbito externo, justificativo, de la norma y se manifiesta como un juicio presuntivo realizado por el legislador (como fundamento de la norma que establece). En este sentido las presunciones absolutas no serían normas que establecen una presunción en su contenido, sino normas basadas en un razonamiento presuntivo".

29. Véase Alchourrón \& Bulygin 1983.

30. Sistema normativo entendido como el "subconjunto del ordenamiento formado por aquellos enunciados válidos que son relevantes para la materia que interesa elucidar" (Alchourrón \& Bulygin 2006 [1971]: 122).

31. Por cierto, presentar así al sistema normativo presupone la interpretación de ciertos materiales jurídicos, y ello no es indiscutible: parte de lo que los reduccionistas estarían diciendo es que esas interpretaciones solo oscurecen la real entidad de la cuestión. Esto último es lo que intentará rebatirse.

32. Es decir, asumamos que el ordenamiento contiene dos disposiciones $D_{1}$ y $D_{2}$ que, al menos respecto de $\mathrm{S}_{1}$, iteran a las normas $\mathrm{N}_{1} \mathrm{y} \mathrm{N}_{2}$. Esto permite mostrar que hay otras alternativas interpretativas. No quiero, en cualquier caso, ingresar en la polémica sobre si alguna técnica de atribución de significado tiene prevalencia - ya conceptual, ya normativa - a efectos de la interpretación decisoria.

33. Estas normas habrían de leerse del siguiente modo: $\mathrm{N}_{1}$ : 'quien ejecute la acción A deberá ser condenado a C'. $\mathrm{N}_{2}$ : 'si se verifica $B$ debe presumirse, sin posibilidad de prueba en contrario, que se ejecutó la acción A'. Como es evidente, estoy simplificando una gran cantidad de cuestiones. Por ejemplo, estoy omitiendo el cuantificador universal en la formalización y estoy dando por hecho que tanto A cuanto B son predicables del mismo agente. Además, dado que este texto se centra en las normas que enlazan acciones con consecuencias punitivas, asumiré que todos los antecedentes de las normas refieren a conductas (y no a otros eventos o estados de cosas). Por otro lado, por razones de simplificación estoy omitiendo también hacer explícita la distinción entre las acciones (A o B) y las proposiciones referentes a la ocurrencia de aquellas. Debe tenerse presente que las normas prohíben, permiten o mandan a realizar acciones, pero lo que se prueba o acepta como verdadero son las proposiciones a esas acciones referentes.

34. Aguiló Regla 2006: 27. 
35. “... I cannot envisage any circumstances in which a straightforward substantive provision would not be preferable to the circumlocutory procedural 'equivalent'. Perhaps demagogues seeking to conceal the ideological content of their criminal legislation would find merit in the use of an irrebuttable presumption. For the conscientious legislator, however, irrebuttable factual presumptions are at best superfluous, and at worst a menace" (Roberts 2005: 184-185).

36. Gama Leyva 2013: 77.

37. Olshausen 1943: 316. En términos semejantes, Taruffo 1991: 1 al pronunciarse sobre las PA en el ámbito procesal civil.

38. Schauer 2013: 230.

39. Cfr. Schroeder 2018: 58

40. Cfr. Mendonca 2006: 12.

41. Véase Fuller 1967: 37, también en Fuller 2006 [1967].

42. Hay quienes han sugerido que todas las presunciones han de reducirse a ficciones jurídicas. Es sugestivo que uno de los sostenedores de la tesis reduccionista respecto de las $P A$, rechace de plano la identificación entre presunciones (tout court) y ficciones. El argumento alegado es que, así entendido el reduccionismo, todas las presunciones son tan ficciones cuanto toda otra regla jurídica (Schauer 2015). Sobre la distinción aquí enfatizada entre PA y ficciones jurídicas, véanse, además de los citados trabajos de Fuller: Gascón Abellán 2004: 149, Mendonca 2006: 17-19, Ross 2006: 112, 118, Tuzet 2011: 531.

43. El propio Schauer 2013: 230 indica esta circunstancia.

44. Véase Ross 2006: 108.

45. Para ver la enorme cantidad de matices a que esto podría conducir, pueden contrastarse, por ejemplo, Kelsen 2006 [1919], §§ II y III, Quinn 2013, Schauer 2015, Chiassoni 2019b, cap. VIII.

46. Duff 2007: 240, en la línea de la posición clásica de Wigmore (1923, §2491) que resuena, por ejemplo, en Morgan 1937, Roberts \& Zuckerman 2004: 341, Roberts 2005, Macagno \& Walton 2012: 281, Stumer 2018. En el ámbito continental, véanse, por ejemplo, Fabbrini 1996, para quien las presunciones absolutas tornan equivalentes dos supuestos de hecho, y Serra Domínguez 1963. Un minucioso análisis de la bibliografía reduccionista distinguiendo los dos ámbitos en Gama Leyva 2019, §§ 3.1 y 4.2.1. Véase también Roland Matida 2019.

47. Emplear a las justificaciones subyacentes como criterios distintivos de los diferentes fenómenos a que se refiere con el ambiguo término 'presunción' es una idea presente, al menos, ya en Morgan 1931. Esta estrategia, aunque dirigida al análisis de las ficciones, parece estar también en el núcleo de Fuller 1967.

48. Ullman-Margalit 1983: 157 ss.

49. Véase Ferrer Beltrán 2005: 47.

50. Sobre el punto Gascón Abellán 2004: 141, Bayón Mohino 2008: 5, nota 7.

51. La norma jurídica sería una especie de blindaje al cuestionamiento de la generalización empírica y la tornaría prueba suficiente e incuestionable: "[l]as presunciones pueden verse como máximas de experiencia institucionalizadas y autoritativas; si se ven de esta manera - y si su fundamento es cognoscitivo, lo que no siempre es así - también deben estar bien apoyadas por una inducción sólida" (González Lagier 2013). En este caso, las presunciones iuris ofician de prueba tasada.

52. Ver también sobre el punto Ullman-Margalit 1983: 158.

53. Wróblewski 1967: 18, Gascón Abellán 2004: 139. Entre quienes se ocupan de las cuestiones epistémicas en el marco jurídico es hoy un lugar común el de reconocer que la suficiencia probatoria no puede estar nunca determinada tan solo por consideraciones de carácter epistémico. Lo que determina la suficiencia de ciertas pruebas en favor de ciertos enunciados y en determinado contexto son juicios evaluativos, axiológicos, respecto de la distribución del riesgo de error. De modo que, así las cosas, lo cierto es que también toda presunción hominis requerirá de consideraciones normativas a efectos de poder ser considerada suficiente en términos 
justificativos de la pretensión a que conduce. No estoy diciendo que la cuestión de los estándares de prueba deba ser equiparada a las presunciones iuris, pero sí quisiera señalar al menos esta semejanza: en uno $u$ otro caso, será indispensable recurrir a consideraciones evaluativas. El hecho de que la suficiencia probatoria esté determinada por una evaluación relativa a la justicia de cierta distribución es lo que torna inadecuada a la equiparación de Fuller entre PA y ficción acerca de la suficiencia probatoria a la que se hace referencia en nota 53. Pues, en este sentido, la suficiencia es siempre 'ficticia'. Sobre la naturaleza de la suficiencia probatoria y su relación con la distribución del riesgo de error véanse, Laudan 2006, Bayón Mohino 2009, Ferrer Beltrán 2013.

54. Ullman-Margalit 1983: 161. A más de ello, también suele haber consideraciones de carácter procedimental que justifican el establecimiento de presunciones iuris

55. Se trataría, en este sentido, de una de esas estipulaciones que procuran definir un término preexistente "de un modo más preciso con respecto al uso común" (Guastini 2018: 17). También en Guastini 2013b.

56. Véase Green 2005: 15.

57. Obsérvese que lo importante es la estructura del argumento, especialmente el hecho de que su garantía se identifique con una norma susceptible de ser reconstruida como presuntiva iuris et de iure en virtud de la conjunción de razones que hacen a su justificación subyacente. En este sentido, como se dijo en la nota 1, puede haber una norma de PA (y, por tanto, un argumento presuntivo iuris et de iure) sin que la palabra 'presunción' figure entre las premisas ni en las disposiciones de donde, eventualmente, ellas se extraen.

58. El modo en que esta prohibición opera es el siguiente: obstaculizando el ingreso al procedimiento de toda evidencia dirigida a probar la proposición presumida. En este sentido, podría decirse que se trata de una prohibición de objeto de prueba que torna inadmisible todo medio probatorio dirigido a probar el enunciado presumido. Decía hace ya muchos años Best: “... when restrained within due limits, they exercise a very salutary effect in the administration of justice, by throwing obstacles in the way of vexatious litigation, and repressing inquiries on subjects where sound and unsuspected evidence is not likely to be obtained" (Best 1845: 36).

59. Fuller 1967: 42 sugiere que las conclusive presumptions, i.e. las PA, son 'ficciones' en el sentido de que decretan que cierta consideración (por caso, B) es prueba suficiente en favor de un enunciado fáctico (por caso A) a sabiendas de que esa suficiencia es falsa, es decir, sabiendo que la prueba es insuficiente o que no es prueba en absoluto. Se mostrará más adelante, al hablar de 'suficiencia probatoria' por qué esta afirmación puede ser rechazada, pero ha de tenerse en cuenta que lo 'ficticio' aquí es algo bien distinto respecto del evento al que el enunciado fáctico en cuestión refiere. Véase, sobre la distinción entre normas de decisión y normas de conducta, Dan-Cohen 1984.

60. Esta tesis ha sido sostenida con meridiana claridad, específicamente respecto de las conclusive presumptions [PA] y de su diferencia con las offence definitions, por Plaxton 2010. A la posición que trato como reduccionista, él la llama ortodoxa. Al margen de cuanto se dirá más adelante, para Plaxton, la distinción conceptual cobra relevancia práctica en virtud del interés estatal en enviar distintos mensajes a la ciudadanía y a los potenciales decisores.

61. Gama Leyva 2013: 79. Véase también Gama Leyva 2015.

62. Sobre estas dos estrategias: Mendonca 1998: 96-98.

63. Aguiló Regla 2018: 222.

64. Véase Gascón Abellán 2004: 150-151: "las presunciones [iuris et de iure] al impedir toda ulterior investigación, logran efectos análogos [a los de las ficciones] pero operando sobre los hechos, pues aquellos que se presumen como ciertos no admiten ni siquiera emprender una tarea de investigación o conocimiento. Cabe decir que la ficción es un problema de calificación normativa; las presunciones, un problema de hechos [...] las presunciones iuris et de iure son normas que, para la protección de ciertos valores y en presencia de determinadas circunstancias, establecen el 
particular efecto jurídico de dar por verdaderos ciertos hechos y no transigen con ninguna excepción no prevista".

65. Ullman-Margalit 1983: 150.

66. Ullman-Margalit 1983: 150, nota 7.

67. Schauer 2013: 230-231.

68. En efecto, la norma presuntiva prescribe la acción (de aceptar el enunciado) antes de concluir la deliberación (Ullman-Margalit 1983: 155). Este es, como vimos, el punto en el que enfatiza Schauer para reducir las llamadas presunciones irrefutables a simples reglas (véase la nota 25).

69. Esto es: (i) que el hecho base B es un indicio de la verdad el enunciado presumido A al tiempo que (ii) un estándar normativo obsta seguir profundizando en la indagación acerca de si A es o no efectivamente el caso en cada ocasión en que se verifique B.

70. "Challenging the presumption rule would be pointless in both presumptions of law and presumptions of fact. In the first case, it would amount to challenging a law; in the second case, it would be meaningless to prove the defeasibility of an inference which by nature is rebuttable" (Macagno \& Walton 2012: 292). Si bien en este pasaje los autores refieren a las presunciones iuris tantum (pues, como se ha visto, ellos rechazan a las iuris et de iure como genuinas presunciones), dejan entrever que entienden que challenging a law sería una operación destinada al fracaso.

71. Tal como reconoce, por lo demás, el propio Schauer: véanse, al menos, Schauer 1988, Schauer 2013: 175-176, Schauer 2015.

72. Si así no fuere, poca relevancia habría poseído, por ejemplo, la conocida objeción al modelo de las reglas al tiempo que ningún sentido habría tenido dedicarle esfuerzo alguno a responderla. Véanse, en general, Dworkin 1967, Hart 2012, Dworkin 2013 [1977].

73. Véanse Schauer 1991, Bouvier 2004.

74. Rodríguez 2002, Alchourrón \& Bulygin 2006 [1971]: 376.

75. Rodríguez \& Sucar 1998, Bayón Mohino 2000, Navarro \& Jorge 2000, Navarro \& Rodríguez 2000, Alchourron 2000 [1996], Celano 2002, Guastini 2008: 109, Guastini 2010, Ferrer Beltrán \& Ratti 2012, Strahovnik 2016.

76. De entre la vastísima bibliografía al respecto, pueden verse, Alexy 1994, Atienza \& Ruiz Manero 1996, Celano 2002, Maniaci 2002, Moreso 2002, Prieto Sanchís 2003, Atienza 2005, Celano 2006, Moreso 2006, Martínez Zorrilla 2007, Moreso 2007, Alexy 2008, Pino 2009, Atienza 2010, Dworkin 2013 [1977], Moreso 2017, Guastini 2018, cap. IV, § 4 de la cuarta parte.

77. Guastini 2013a.

78. Véase, entre muchos, Laporta 2007: 199 y ss.

79. De entre la numerosísima bibliografía al respecto, por ejemplo, Dworkin 1986, Alexy 1994, Atienza \& Ruiz Manero 1996, Bayón Mohíno 1996, Celano 2002, Maniaci 2002, Moreso 2002, Prieto Sanchís 2003, Atienza 2005, Celano 2006, Moreso 2006, Martínez Zorrilla 2007, Moreso 2007, Alexy 2008, Pino 2009, Atienza 2010, Dworkin 2013 [1977].

80. Véanse Tarello 1980, Guastini 2004, Guastini 2011, Chiassoni 2019b, Chiassoni 2019a.

81. "Esto muestra la importancia de ponerse de acuerdo acerca de qué normas (es decir, acerca de qué sistema normativo) se está hablando...” (Alchourrón \& Bulygin 2006 [1971]: 47).

82. Sobre este punto véase Guastini 2011, cap. IV § 2.

83. Véase sobre el punto Ferrer Beltrán 2007: 52-59, además de la legislación, jurisprudencia y doctrina por él citados en ese apartado.

84. Por lo demás, esta reconstrucción del sistema normativo es perfectamente posible incluso en casos en que la única disposición presente fuera $\mathrm{D}$, es decir, en ordenamientos modestos como OJ. Pues aun cuando la norma extraíble de D pudiera resultar inconstitucional si entendida como una prohibición de la acción que funge de supuesto de hecho, ella podría ser redimida si esa acción fuere entendida como hecho base de una presunción iuris et de iure.

85. Resuenan aquí las palabras de Nino "el Poder Judicial no puede ser sustituido o restringido en su responsabilidad de determinar la real ocurrencia de hechos particulares. Esa responsabilidad 
es lo que lo hace genuinamente independiente y la que lo habilita para llegar a soluciones justamente independiente y la que lo habilita para llegar a soluciones justa en los casos particulares. Como dice Ferrajoli, la verdadera independencia del Poder Judicial está fundada en que él se guía por el principio veritas, non auctoritas facit iudicium, invirtiendo el principio hobbesiano, válido para la legislación, auctoritas non veritas facit legem; esto implica que el consenso democrático no puede funcionar como criterio de verdad fáctica para fundamentar la legitimidad jurisdiccional. Son incompatibles con los principios de tener una democracia liberal las leyes que preconstituyen hechos particulares, creando ficciones o presunciones iuris et de iure (...) ellas implican que los poderes políticos se arrogan una función inherente al Poder Judicial" (Nino 2005: 449-450). Cfr. las consideraciones de Aguiló Regla 2006: 28 y véase, aunque con una noción mucho más vaga de PA [conclusive presumption] Ackerman 1977.

\section{ABSTRACTS}

According to the classical view, conclusive presumptions are nothing but an abstruse way of referring to substantive rules. At most, the peculiarity of these putatively alleged presumptions would be that they are devices from which one can infer substantive rules. Hence, according to the classical view, conclusive presumptions are not presumptions at all. This paper shows that, despite its wide acceptance, the classical picture is misleading. The article indicates where the presumptive nature of the conclusive presumptions lays. In addition, it highlights the enormous practical relevance of conclusive presumptions so conceived.

La tesis según la cual las expresiones 'presunciones absolutas' o 'presunciones iuris et de iure' no son más que un modo abstruso de referir a reglas sustantivas prohibitivas de ciertas conductas se ha vuelto un lugar común entre juristas. A lo sumo, se sostiene, la peculiaridad de esas presunciones putativas radicaría en que son dispositivos que permiten inferir reglas sustantivas. De aquí que muchas veces se niegue sin más a las iuris et de iure el carácter de auténticas presunciones. Este artículo muestra que, a pesar de su amplia aceptación, esta tesis está desencaminada. En primer término, se indica dónde reside el caracter presuntivo de las presunciones absolutas o iuris et de iure. En segundo lugar, se hace explícita la peculiaridad de este tipo de presunciones. Por último, se demuestra que ellas poseen una enorme relevancia práctica dentro de la praxis jurídico argumentativa.

\section{INDEX}

Keywords: presumption, conclusiveness, argument, proof

Palabras claves: presunción, iuris et de iure, argumento, prueba

\section{AUTHOR}

\section{DIEGO DEI VECCHI}

Investigador Juan de la Cierva en la Universitat de Girona, España 
Address: Universitat de Girona - Facultat de Derecho - Campus de Montilivi - 17003 Girona España

E-mail: deivecchidm@gmail.com 